HIDDEN VOICES:

\title{
PROFESSIONAL CHORISTERS IN SOUTHERN ONTARIO
}

by

ANDREW WALKER, B.A. HONOURS

A thesis submitted to Carleton University in fulfillment of the requirements toward the degree of Master of Arts in Canadian Studies

School of Indigenous and Canadian Studies

Carleton University

Ottawa, Canada

May 15, 2021

(C) Copyright, 2021, Andrew Walker 


\section{CONTENTS}

$\begin{array}{ll}\text { Introduction } & 1\end{array}$

Chapter 1 Choristers and Cultural Paradigms - A Brief History 17

Chapter 2 The Nature of the Work 38

$\begin{array}{lll}\text { Chapter } 3 \quad \text { Defining the Professional Chorister } & 60\end{array}$

$\begin{array}{lll}\text { Chapter } 4 & \text { Institutions and Structures } & 79\end{array}$

Conclusion Considerations for an Artist-Centric Model of Cultural Policy 111

$\begin{array}{lr}\text { Bibliography } & 118\end{array}$

Appendix A: CUREB A Clearance Certificate $\quad 127$ 


\section{FIGURES}

Figure 1: Economic and Musical Capitals - Professional Chorister, Walker 68

Figure 2: $\quad$ Percentage of Total Income Emanating from Professional Choral Music, prior to COVID-19

Figure 3: $\quad$ Number of Hours per Week of Work as a Professional Chorister prior to COVID-19

Figure 4: Number of Days per Week of Work as a Professional Chorister prior to COVID-19

92

Figure 5: $\quad$ Minimum Pre-Tax Hourly Rate Accepted for Professional Choral Work 


\begin{abstract}
Research has shown that choral music is a popular and persistent art form in Canadian life, yet little inquiry has been undertaken to better understand those who work in the field. This thesis sheds light on professional choristers in southern Ontario in an effort to dispel their shadowy status in both scholarly research and cultural policy. This status is a product of the culture of the choral arts sector that is inculcated by training and workplace institutions and internalized in the individual chorister's selfconceptualization. As workers in an inherently communal, community-based, and accessible art form, these choristers are ill matched with the contemporary logic of cultural policy. Through a methodology combining interviews with professional choristers and autoethnography, this thesis outlines their lived experiences and offers a glimpse of what an artist-centric federal cultural policy could be.
\end{abstract}




\section{Introduction}

The inherent beauty of singing in a choir is its anonymity. For all the individual time a singer has put into their music and craft, be they volunteer or professional, the end result of a performance is a group of voices forming something greater than its individual parts. There is a comfort in this, a safety in numbers, be it in a symphonic ensemble of hundreds of voices, accompanying an orchestra of many more, or a mere quintet, embracing the nimbleness of a madrigal. The likelihood is that at the end of a

concert, the audience can pick out only a handful of people, one of whom was probably the person waving their arms on the podium in the front. The low bass, who growled out Rachmaninov's low B flat; the first tenor, who prayed his voice would pump out one last high A before he retires; the mezzo soprano, misplaced as a second alto, valiantly delivering the goods below the staff; the first soprano, gingerly placing the straight-toned melody exactly in tune: each of them brings with them a unique background, skills, and challenges that go unheard and unseen in the spectacle of a choir.

Choral art requires performers' connections with one another to extend beyond the technical demands of the music. Its collaborative nature deflects attention from the individual artists whose voices are submerged in the communal harmony. Indeed, the anonymity of professional choral work is what attracts some performers to it. Those with incredible artistic ability who might wilt as a soloist at the centre of attention can thrive sharing the spotlight with other talented musicians.

In a liberal culture that celebrates individual achievement, choristers are overlooked. Just imagine how long it would take in any general discussion of Canadian culture for choirs to arise as a consideration. Not surprisingly, for cultural policy makers, 
choirs are barely on the radar screen. Yet culture is supposed to be communal, something we share that binds society together. From this perspective, choristers are cultural workers par excellence. Their work is grounded in local communities and they work cooperatively. There is a case to be made that they should be a model cultural activity for all branches of the arts.

This paper is an initial probe of a largely unknown cultural landscape. Focusing on professional choristers in southern Ontario, its multipurpose agenda is to rescue them from obscurity, identify their issues, and situate them in the contemporary cultural and cultural policy landscape. It sheds light on the choral music ecosystem in southern Ontario, revealing the oft-overlooked popularity of singing in and listening to choirs. It then focuses on professional choristers, the most accomplished artists in the field, examining their employers, career patterns, and the challenges they face. It argues that they are a class of cultural workers who are ill aligned with and ill served by federal government cultural policy.

\section{Literature Review}

The significant international scholarly literature on musicians in general and voice artists more specifically is too extensive to cover comprehensively here. What follows is a summary of some of the works that have proven most useful for framing this study. Stephen Cottrell's Professional Music-Making in London: Ethnography and Experience has greatly influenced my conceptualization of this research project. It alerted me to important themes in the field, and its autoethnographic approach to understanding 
professional musicians in their community and career contexts provided me with a model of how to conduct my research. ${ }^{1}$

Alan Merriam's seminal work, The Anthropology of Music, includes a chapter on the jazz musician which suggests that the social positions of these individuals are characterized by a low economic status compared to their relatively high level of importance and profile in society. As creative workers they contribute to the general welfare by producing cultural experiences that provide others with entertainment, pleasure, and reflection. He also notes that they often exhibit patterns of behaviour that are somewhat deviant yet still within the bounds of what is socially permissible (drinking is the example pointed to here). ${ }^{2}$ Howard Becker is another writer who has studied musicians and their work culture. He emphasizes the gulf separating the musician or dancer and their audience, whose members are characterized by the performers as "squares."3 The performers of Becker's study define themselves in opposition to "squares," rejecting conventional society and commercialism. ${ }^{4}$

Dawn Bennett's discussion of professional classical instrumental musicians alludes to the dearth of research on the lives of individuals in the musical profession and the employment conditions they encounter, including attrition in the field, the real risk of injury, both physical and psychological, and the underrepresentation of women in orchestras. ${ }^{5}$ Ruth Towse has studied singers in the context of their labour marketplace,

\footnotetext{
${ }^{1}$ Stephen Cottrell, Professional Music-Making in London: Ethnography and Experience (Burlington: Ashgate Publishing Company, 2004), 15-16.

${ }^{2}$ Alan Merriam, The Anthropology of Music, (Evanston: Northwestern University Press, 1964), 137.

${ }^{3}$ Howard Becker, "The Professional Dance Musician and His Audience," American Journal of Sociology 57, no.2 (1951): 142.

${ }^{4}$ Ibid.

${ }^{5}$ Dawn Bennett, Understanding the Classical Music Profession: The Past, the Present and Strategies for the Future (Burlington: Ashgate Publishing Company, 2008), 33-55.
} 
evaluating economic factors such as supply, demand, and the rate of return they get on their investment in professional training. ${ }^{6}$

To better understand the context in which choral music developed in Canada, I have drawn upon historical studies of Canadian culture and cultural policy. Helmut Kallmann's sweeping history of Canadian music provides a broad context for understanding the place of choirs in the country's past. ${ }^{7}$ Maria Tippett's history of culture in Canada prior to the Massey Commission offers further background context. ${ }^{8}$ The cultural landscape of early Canada featured a local community-based culture with a participatory ethic. Culture was deemed a form of self-improvement and defined in opposition to the rising mass culture of the early twentieth century. Paul Litt's and Dot Tuer's work on Canadian culture and cultural policy in the wake of the Second World War shows how in responding to the perceived threat of American mass culture the Massey Commission directed cultural policy away from a local community-based approach towards supporting a national culture focused on public media ownership to ward off American mass culture and foster high culture..$^{9}$ Ryan Edwardson's Canadian Content traces how subsequent cultural policy developed a cultural industries approach that replicated American entertainment industries and defeated the purposes of Massey-era cultural nationalists. ${ }^{10}$

\footnotetext{
${ }^{6}$ Ruth Towse, Singers in the Marketplace: The Economics of the Singing Profession (Oxford: Clarendon Press, 1993).

7 Helmut Kallmann, A History of Music in Canada 1534-1914 (Toronto: University of Toronto Press, 1960).

${ }^{8}$ Maria Tippett, Making Culture: English-Canadian Institutions and the Arts before the Massey

Commission (Toronto: University of Toronto Press, 1990).

9 Paul, Litt, The Muses, the Masses and the Massey Commission (Toronto: University of Toronto Press, 1992); Dot Tuer, "The Art of Nation Building: Constructing a Cultural Identity for Post-War Canada," Parallelogram, 17, 4 (1992).

${ }^{10}$ Ryan Edwardson, Canadian Content: Culture and the Quest for Nationhood (Toronto: University of Toronto Press, 2008),
} 
These works both set the jurisdictional level of analysis of cultural policy at the federal level and underpin one of the main arguments of this paper. It rests on the premise that over the course of Canadian history there has been a paradigm shift in performative culture, and, consequently, related cultural policy, from a participatory, community integrated model to the cultural industries model critiqued by Edwardson. This distinction is, admittedly, a generalization (not to mention a simplistic binary), yet for all their faults, such categorizations are useful tools of analysis. To refine the distinction somewhat, it is important to recognize that the latter was present in the former, and that the former remains a part of the latter. Raymond Williams' language of emergent, dominant, and residual forms of culture can be adapted to help describe this change of cultural regimes. ${ }^{11}$ Choral music was an integral part of the first paradigm when it was dominant and the second paradigm emergent. Eventually the first paradigm became residual and the second dominant, and under this regime choral music has fared relatively poorly. I argue that as a result of policy choices made over seventy years ago, the cultural workers embedded in this inherently communal and accessible form of artistic output have been hidden from and misunderstood by decision and policy makers in Canada.

As a venerable, if not downright old-fashioned, form of culture, choral music bears a lot of antiquated cultural baggage. To attend an Anglican cathedral service on a high holiday and hear its elite choir perform a favourite hymn is an experience that could be taking place anywhere in the Western Anglosphere any time during the past century or more. One is reminded of Faulkner's aphorism: "The past is not dead. It is not even

\footnotetext{
${ }^{11}$ Raymond Williams, Marxism and Literature (Oxford, 1977), 121-6.
} 
past." In a secular culture that prides itself on being inclusive of different cultures and peoples from around the world, Canadian choral music shows its roots in an older Canada. Its practitioners were and remain overwhelmingly white. It is heavily influenced by its European antecedents. Moreover, Christian churches remain hotbeds of talent development and leading patrons of professional choristers. At least choirs, today as in the past, do not discriminate on the basis of gender or sexual orientation (castratos excepted). The desire for a blend of different voices has, in many though not all cases, mandated gender equity.

Choristers, then, present us with some intriguing conundrums. They are consummate collaborators in an era that celebrates the genius of the individual artist. They exemplify a participatory culture that is the antithesis of the couch potato so vilified as an avatar of modern alienation. They are grounded in an art that has higher rates of popular participation of any in the country, yet their profile in mass mediated entertainments or government cultural subsidies is negligible.

\section{Methodology}

To investigate the state of the art I have devised an approach that combines the insights and context provided by secondary studies with primary research based on interviews of professionals in the field and auto-ethnography. Over the course of late April and early May 2020, I interviewed twenty-four individuals with whom I have previously worked in a professional choral music setting. Previous to conducting this research, I received ethics clearance from the Carleton University Research Ethics Board (see 
Appendix A for proof of approval of my project). The interviewees were selected by a using my contacts in the Toronto choral community to identify prospects and then evaluating them with the goal of achieving a broad representative sampling of career experiences in the field. I chose to leverage my personal contacts to this end for two reasons. First, the willingness to participate was likely to be higher when we knew one another. Second, my experience in the professional choral music scene offered some guidance on how to achieve a balance of perspectives and experiences (i.e., work with different choirs, as a soloist, in different regions of the country, etc.). I was aware of the risk that ease of access to certain people or personal biases could affect my selection of study participants and skew my sample and made a conscious effort to negate such factors.

I also strove to have my sample represent a relative balance in voice parts. I ended up with seven sopranos, seven altos or countertenors, four tenors, and five baritones or basses. Interview participants are identified herein only by their voice part to enable their candour, protect their privacy, and avoid any risk of negative employment or social ramifications. The interviews were originally supposed to be conducted in person, a plan that was swiftly foiled by the COVID-19 international pandemic. While imperfect technological capacities often interrupted the conversations, I am grateful to the participants in this study for their patience and willingness to offer their thoughts and experiences.

In addition to the interviews, participants were offered a confidential survey, hosted by Google Polls, which elicited granular details, including salaries, allotment of time, and work outside of choral music. Responses came from twenty-eight individuals, 
of whom ten identified as a soprano, six as an alto or countertenor, seven as a tenor, and five as a bass. The group of survey respondents was not exactly the same as the group of interview respondents because some of the choristers I approached chose to participate solely in the former while others responded to the survey following the close of interviews in mid-May. I am grateful to those who took the time to respond to the survey with thoughtful comments and ideas for this project.

The research for this project was based around three guiding research questions: 1) what is a professional chorister? 2) what challenges do professional choristers face? and 3) based on this knowledge, what might policymakers consider to sustain and grow professional choral music across the country?

In addition to interviews, my research incorporates an auto-ethnographic approach. In Professional Music-Making in London: Ethnography and Experience, Stephen Cottrell described himself as a "native anthropologist," by which he meant someone who "describes those who study a particular group or culture to which they themselves already belong." I consider myself to be a native anthropologist for the purposes of this study. Cottrell enumerates the many benefits of this approach. The native anthropologist is already immersed in the language and conventions of the group they study. They enjoy privileged access to interviewees and other sources of information. Their own personal history can be a rich source of data. Their preexisting knowledge is invaluable in guiding the formulation of research questions and conclusions. ${ }^{12}$

\footnotetext{
${ }^{12}$ Cottrell, Professional Music-Making, 15-17.
} 
Of course, the benefits offered by this approach are also accompanied by potential risks. One is that the researcher's personal experience and knowledge extends beyond the scope of information elicited by the interview questions. Another is that it is necessary for the native anthropologist to denaturalize insider beliefs and practices they are conditioned to take for granted. The native anthropologist risks, as Mascarenhas-Keyes writes, "professionally induced schizophrenia between the "native self" and the "professional self" in an effort to see one's own culture as strange and worthy of study. ${ }^{13}$

Cottrell's native anthropologist is a type of autoethnographer. Autoethnography is a qualitative research methodology that draws on the researcher's personal experiences to study a community to which the researcher belongs. It "use[s] our experience to engage ourselves, others, culture(s), politics, and social research." ${ }^{14}$ It must be reflexive to offset the subjective biases that accompany personal experience. The autoethnographer must be self-aware, stepping back to appreciate the intersections between themselves and society. The risks inherent in this approach are worth taking in order to get an intimate view from within a community. It offers greater potential than most conventional methodologies for a holistic understanding of the phenomenon under examination.

There are also advantages to having interviews conducted by a community member. Interviewees may be guarded in dealing with outsiders because they suspect their motives or fear that they will be incapable of understanding their experience.

\footnotetext{
${ }^{13}$ Ibid., 16; Stella Mascarenhas-Keyes, "The Native Anthropologist: Constraints and Strategies in Research," in Anthropology at Home, ed, Anthony Jackson (London: Tavistock, 1987), 180.

${ }^{14}$ Tony E. Adams, Holman Jones, Stacy Linn, and Carolyn Ellis, Autoethnography: Understanding Qualitative Research (New York: Oxford University Press, 2015), 2-3.
} 
Having an insider interview is a way to tap into the lived experience of marginalized groups. ${ }^{15}$ If the autoethnographer consciously applies an intersectional approach, they can keep matters of race, class, sex, gender, sexuality, and other identity factors in mind as they conduct their research.

In order to offset the subjective biases of the native anthropologist, it is important to be reflexive and acknowledge one's positionality. With that in mind, I present the following autobiographical information. In the second grade, I, along with each of the other boys in my class, unwittingly participated in an audition with the then Director of St. Michael's Choir School, based in Toronto, Ontario. ${ }^{16}$ From the third grade until my graduation from secondary school in 2013 , I attended the Choir School, participating in daily lessons in choral music, weekly private lessons in piano and voice, weekly church services (from fifth to twelfth grade), and concerts and tours from Massey Hall in Toronto to an audience with Pope Francis in 2013. The education at the Choir School, a semi-private school, provided me with technical skills in choral music-making. I grew familiar with a wide repertoire, both in voice part as I personally transitioned through treble and alto to arrive at my tenor range and the choirs themselves transitioned from higher voices only to the full choir of Soprano-Alto-Tenor-Bass, henceforth referred to as SATB). I learned about time period. I gained musicianship skills, including sightreading, music theory and harmony, and blend, a topic of greater discussion later in this

\footnotetext{
${ }^{15}$ Robin M. Boylorn and Mark P. Orbe, Critical Autoethnography: Intersecting Cultural Identities in Everyday Life (Walnut Creek: Left Coast Press, Inc., 2014), 13.

${ }^{16}$ Audition is a loose term and implies some self-determination in the heart of the auditioned: the St. Michael's Choir School Director, as part of the process still entitled Bambino, asked the boys in the second-grade class to sing a line of ' $O$ Canada'. Those deemed worthy received a letter to attend a further audition, which included a second vocal audition, in addition to an academic aptitude test. While my parents may have been aware of the potential ramifications of this process, I was certainly unaware of what I was signing up for by participating in the auditions.
} 
piece. Working as a professional musician, I gained experience with international tours, solo opportunities, live broadcasts and album recordings and a grounding in singing techniques, including breathing, posture, and tone production.

Following my time at St. Michael's Choir School, I was offered a choral scholarship at Truro Cathedral in the United Kingdom. I was hired as a professional choral musician to participate in six weekly religious services, religious holidays and associated concerts, live broadcasts and recordings, and tours around the diocese. This was a seminal experience in work as a professional musician. I "lived" the Anglican choral tradition, rehearsing and performing with lifelong professional choristers and treble choristers of the highest quality. There is no equivalent deep immersion experience in North America. ${ }^{17}$ The Truro Cathedral Choir had the time to consistently rehearse, perform, and then record pieces of music over a prolonged period. It was like a football team that practices each day, not because its players need the time to learn the playbook, but rather to establish a camaraderie and an inherently understood chemistry. For an Anglican cathedral choir, this chemistry translates loosely to the "house style": a rhythm, pace, and idiosyncratic interpretation of standard components of the repertoire such as the minimally notated Anglican chant, Baroque dotted quarter notes, Howellsian hanging quavers, or the rubato, which may be written in the score or glossed on to it to accommodate the acoustics of the cathedral. My choral scholarship experience engendered a sober appreciation of the life of a professional chorister in the Anglican choral tradition, one that I found immensely rewarding while making music but otherwise tedious and monotonous.

\footnotetext{
17 Truro Cathedral provided lodging for choral scholars, a house creatively named the 'Scholary' or, at moments of true embarrassment, the 'Squalory'.
} 
Upon my return to Canada in August of 2014, I began my undergraduate degree in political science and Canadian studies at Glendon College of York University. By January of 2015, I had auditioned for and landed regular work at St. Clement's Anglican Church in Toronto and as a substitute in weddings, funerals, and other ad hoc choral music work. Later that year, I landed what became my three regular choral roles over the coming years: the Cathedral Choir, and later the Parish Choir, of the Cathedral Church of St. James, the Toronto Mendelssohn Choir, and the Elora Festival Singers, now renamed to The Elora Singers. Other gigs came and went, including with the Theatre of Early Music, Tallis Choir, Toronto Chamber Choir, Choir 21, two international music festivals (Bachakademie Internationale Stuttgart and Bachakademie Weimar), and choir work at a variety of Anglican and Roman Catholic churches.

In subsequent years, my three regular roles filled most weeks with multiple rehearsals and performances accompanied by socializing with associated communities of colleagues and peers, many of whom became friends. My regular employers each represented a distinct type of choral work. One was a religious institution, or "the church gig" (St. James). Another was a community or symphonic choir, otherwise known as "section leading" (Toronto Mendelssohn Choir). The third was a chamber or fully professional ensemble. For the following three years, I sang with each organisation, in addition to completing my undergraduate studies and working in part-time jobs in customer service and government.

When I moved to Ottawa, Ontario in 2018 , I elected not to reaudition for the Cathedral Church of St. James and the Toronto Mendelssohn Choir. I did, however, continue to sing with The Elora Singers. I also took occasional work with the Theatre of 
Early Music, the Ottawa Eight, and religious institutions. I also got a job with the Parliamentary Secretary to the Minister of Canadian Heritage, the federal ministry primarily responsible for cultural life and work in Canada. In the fall of 2020, I was named President-Elect of Choirs Ontario. I sit on its Board of Directors, advocating for the preservation and growth of choral music across the province. My most recent role is in advocacy as a consultant with Global Public Affairs, serving as a consultant for cultural industries of varying types from across Canada.

This summary of my professional work is most intended neither as self-promotion nor to establish my credibility as a scholar. It serves to reveal my biases and show that I have a vested interest in the profession of chorister. It is shared with the reader in the hope that it will assist them in evaluating the analysis to come. Armed with this information, it will be for the reader to determine how successfully I have managed the risks inherent in an auto-ethnographical methodology.

In this regard it is worth noting some scholarly perspectives on the relationship between conceptualizing the self and objectivity. Anthony Cohen writes:

Instead of conceptualising the self as a replicate in miniature of society, we could begin by paying attention to the ways in which people reflect on themselves, and then see in what ways these reflections are indicative of social and cultural context or require such contextualisation to be intelligible to us. ${ }^{18}$

The methodological grounding for this paper steers away from generalizing about a group (in this case, treating professional choral singers as a body of arts practitioners). Instead it seeks to privilege the perspectives of individuals, including both researcher and researched, in order to reveal inconsistencies and tensions across the group,

\footnotetext{
${ }^{18}$ Anthony Cohen, Self Consciousness: An Alternative Anthropology of Identity (Routledge: New York, 2002), 29.
} 
hoping thereby to identify notable trends and areas requiring further study. Cohen continues:

Our interpretations of what we witness around us proceed from our own experience, our consciousness, of ourselves, even though we may not be conscious of its peculiarity to ourselves. Anthropologists have to qualify their selfexperience by subjecting it to the disciplines of comparison and of theoretical and methodological rigour. ${ }^{19}$

Cohen would disagree with Bourdieu's assertion that "all the products of a given agent, by an essential overdetermination, speak inseparably and simultaneously of his class." 20 On the other hand, Bourdieu's injunction on the "objectification of objectification" is complementary to Cohen's work. Cottrell summarizes it well. Bourdieu's idea is a theoretical posture in which he suggests that not only should we take a metaphoric step back, to gain an objective vantage point of the subject under study, but we should accompany this with a further step back, to consider our own relationship with the assertions we make about what we study. ${ }^{21}$

While Cottrell structures his book chapters to start at the level of the individual musician, this paper will take a different path. It considers professional choral musicians individually as the primary units of analysis, then induces from the experiences of these practitioners the broader structural issues in play.

There are two methodological issues that remain to be mentioned. First, while geographic proximity was not a selection criterion in a practical sense, as interviews were conducted online, the professional choral musicians who participated in this study work primarily in southern Ontario and the Golden Horseshoe region of Ontario. Further research will be required to discuss the experiences of professional choristers in other

\footnotetext{
19 lbid., 191.

${ }^{20}$ Pierre Bourdieu, Outline of a Theory of Practice (Cambridge: Cambridge University Press, 1977), 87; Cottrell, 24.

${ }^{21}$ Cottrell, Professional Music-Making, 24.
} 
parts of the country, with special reference to Quebec, which, as will be discussed, offers an entirely different institutional structure for its musicians than Ontario.

Second, the timing of this project may limit its applicability. The interviews were conducted during the first wave of COVID-19, a context which undoubtedly affected both interviewees and interviewer. While the evidence collected remains relevant in the pre- and, hopefully, post-COVID world, particular institutions and singers themselves may no longer engage in professional choral music as a result of the economic devastation wrought by the pandemic. I am reassured by news that research is already underway on both the suffering and ingenuity of musicians during the pandemic.

\section{Chapter Outline}

The thesis begins with a chapter that provides an overview of the history of choral music, and in turn, professional choral music in Canada, within the general context of Canadian cultural and cultural policy development. This first chapter then describes the transition from a local, community-integrated and participatory culture towards that of a mass culture and the defensive national cultural policy response it provoked. With this background established, Chapter Two delves into the present-day condition of choral music in Ontario. It draws on the testimony of interviewees to outline a typology of the type of work available to those who work as professional choristers in Southern Ontario. Chapter Three engages with questions of professional selfdetermination and identity. Relying both on the extended academic literature on arts professionals and the interview subjects themselves, it demonstrates how 
determinations of who qualifies as a professional chorister rely primarily on the criteria of economic earnings and employer status, supported by the lesser criteria of virtuosity and field-specific cultural capital. Chapter Four explores the institutions at the heart of the choral music ecosystem and how they structure a precarious work environment for professional choristers. The chapter concludes with considerations of mental health and wellness that emerge from this deeper understanding of a precarious form of cultural work. The conclusion reflects on the major issues raised by this study with a specific focus on whether professional choristers merit greater support and the potential costs and benefits of attaining it. 


\section{Chapter One: Choristers and Cultural Paradigms - A Brief History}

The discipline of history is based on the premise that the past affects the present and we cannot understand any contemporary phenomenon properly without knowing about its past. This approach is particularly appropriate in the case of choral music, which is deeply rooted in traditional social structures, repertoire, skills and practices. This chapter aims to situate Canadian choral music in its historical context as necessary background for appreciating its present-day predicament.

Musicologist Gilles Potvin argues that the breadth and diversity of the choral arts in Canada stem from the religious life of the country, extending back to the French regime, and the delayed development of instrumental music in Canada which concentrated musical expression in the more accessible art of song. ${ }^{22}$ Organized choirs and choral music have a long, rich history across Canada. When Jesuit Paul Le Jeune arrived in Quebec City in 1632, he proceeded to promote music in religious services. Like much of Canadian cultural life, it is unsurprising yet notable that choral music was built on the legacy of settler colonialism. Le Jeune led Indigenous students in a newly formed school in the singing of the Pater Noster (Our Father) at the end of each day. ${ }^{23}$ His contemporary, the famed Ursuline nun Mother Marie de St.-Joseph, led a choir at the local church. ${ }^{24}$ She also taught religious chants, presumably based on the Gregorian

\footnotetext{
22 Gilles Potvin, "Performers," in Aspects of Music in Canada, ed. by Arnold Walter (Toronto: University of Toronto Press, 1969), 160-161.

${ }^{23}$ Helmut Kallmann, A History of Music in Canada 1534-1914 (Toronto: University of Toronto Press, 1960), 16.

${ }^{24}$ Ibid., 16-17.
} 
chants of the Roman Catholic Church, with the accompaniment of a viol. ${ }^{25}$ In 1646 , the first evidence of four-part singing occurred on St. Thomas Day in Quebec City, followed by fauxbourdon (ornamented plain-chant) two years later. ${ }^{26}$

Liturgical and religious music was by no means limited to French Canada. St. Paul's Church of Halifax, which opened for service in 1750, the year after Halifax was founded, represented an early example of an Anglican choir, with a continuous history dating back to the $1760 \mathrm{~s}^{27}$ The Philharmonic Society of Halifax presented an oratorio at St. Paul's Church in 1769, and Quebec City held a series of "Gentlemen's Subscription Concerts" in 1770. In the pre-Confederation colonies of British North America, itinerant singing teachers went from town to town, instructing locals. Their expertise improved the quality of local choirs and provided some measure of standardization in the field.

As the nineteenth century dawned on Canada, the growth of towns and the middle class led to further development of the musical scene. In earlier days music had been largely a "spontaneous amateur activity" or a public performance at church or by a military band. It now became possible to join a choir or instrumental group that performed public concerts. For the first time, music was available as an intrinsic end. In densely populated urban areas, there developed a market for musical instruction and performance that initiated a professionalization process among skilled musicians. ${ }^{28}$ Musical societies and performances proliferated. The historical record is studded with evidence of musical organizations and their performances, whether it was a concert by

\footnotetext{
${ }^{25}$ Marie-Therese Lefebvre, "The Role of the Church in the History of Musical Life in Quebec," in Canadian Music: Issues of Hegemony and Identity, ed. by Beverley Diamond and Robert Witmer (Toronto: Canadian Scholars' Press Inc, 1994), 67-68.

${ }^{26}$ Kallmann, A History of Music in Canada, 17-18.

27 Ibid., 40.

${ }^{28}$ Ibid., 68-69.
} 
the Amateur Glee Club of Halifax in 1837, a performance of Haydn's Creation by the Hamilton Philharmonic Society in 1858, the Philharmonic Society of Victoria performing Singverein in $1859 .{ }^{29}$ In rural communities that lacked a concentration of expertise and paying customers, music-making was more of an amateur affair, integrated with family and community life, that featured folk favourites. ${ }^{30}$ As transportation improved, country folk had better access to urban performances, and metropolitan influences penetrated further into the hinterland.

By the time of Confederation, musical societies were mature institutions with formalized practices. They could boast choirs of two or three hundred voices, drawing talent from regional church choirs. Over the coming years, orchestras and orchestral musicians grew in size and expertise. Their high-profile musical activities were rooted in an increasingly rich musical culture. World-famous artists and companies toured larger centres, musical journals and textbooks circulated widely, instrument making emerged as a viable local industry, and concerts became notable events reviewed in newspapers and periodicals.

By the dawn of the twentieth century, music in Canada was flourishing, with formally organized, professional, semi-professional, and volunteer orchestras in most large cities, professional soloists, and, indeed, established choirs performing public concerts. Kallmann writes: "Every town from coast to coast had choirs of all possible sizes, for church and concert music, singing a cappella or with accompaniment." 31 Voluntary church choirs were the most common choir form before the Second World

\footnotetext{
${ }^{29}$ Helmut Kallmann, "Historical Background," in Aspects of Music in Canada, ed. by Arnold Walter (Toronto: University of Toronto Press, 1969), 44.

${ }^{30}$ Kallmann, A History of Music in Canada, 70.

${ }^{31}$ Kallmann, "Historical Background," 44-54.
} 
War, but large cities witnessed the growth of larger ensembles under the titles of "choral union" or "philharmonic society." 32 Toronto claimed to be the "choral capital of North America," with five large choral organisations, the National Chorus, the Oratorio Society, the Schubert Choir, the Orpheus Society and the Mendelssohn Choir. The last two of these choirs are still in operation. The Mendelssohn Choir has the distinction of being the "first Canadian ensemble to gain an international reputation." ${ }^{33}$ In French Canada musical culture was focused primarily on opera and solo singing at this time, yet it too had its choirs. Organized religion, sociability, and accessibility drove a continuing development of music-making.$^{34}$ Choral institutions, like drama groups and art societies, were organized democratically. Tippett observes that "choirs had no 'stars"' but rather imported soloists from south of the border when necessary. ${ }^{35}$ Professional choristers, at least in secular settings, were nonexistent and incongruous with the nature of choral music at the time.

Yet professionals were evident in other branches of musical culture. They were set apart from amateurs by their ability to earn a living from their craft in the marketplace, a feat that did not prevent them from lobbying the government for assistance. The trend towards professionalization of musicians, including choral groups, was evident in continuing efforts to set and raise standards. The establishment of the Vancouver Music Council in 1923, a group which brought together professional music teachers, along with choral and philharmonic groups, in a standards-raising British

\footnotetext{
32 Durrell Bowman et al., "Choral Singing: Choirs," The Canadian Encyclopedia, 2013, http://www.thecanadianencyclopedia.ca/en/article/choral-singing-choirs-emc/.

${ }^{33}$ Kallmann, "Historical Background," 54-55.

${ }^{34}$ Kallmann, A History of Music in Canada, 203.

35 Tippett, Making Culture, 13.
} 
Columbia Music Festival, was an example of this impulse. By 1938, most professional musicians belonged to the American Federation of Musicians of the United States and Canada. It is unclear, however, whether any choral musicians joined. ${ }^{36}$ While there is little information about choristers, professionalization in the choir sector was evident in the increasing number of musicians employed as church organists and choirmasters. Most were immigrants from Britain who had been trained in its cathedral schools or conservatories. ${ }^{37}$ The Commissioners of the Royal Commission on National

Development in the Arts, Letters and Sciences (henceforth referred to as the Massey

Commission), made note of this contribution decades later:

We might suggest that the work of English organists in Canada from about 1880 to 1920 would form the subject of a valuable social and historical study. ... (T)he work of the scholarly musicians who brought to so many of our smaller towns an important part of the world's great music should not pass unrecorded. ${ }^{38}$

Composers such as Healey Willan, William Henry Anderson, and Alfred Whitehead exemplified the Anglo-Canadian heritage in choral music in the first half of the twentieth century. Of particular note is Dr. Willan, "certainly the best-known Canadian choral composer," "steeped in the English cathedral tradition" (whose music, incidentally, continues to be performed regularly to this day). ${ }^{39}$

A subsequent generation of choral music composers in Canada, including Bernard Naylor, Keith Bissell, and Graham George, remained grounded in the English tradition. ${ }^{40}$ Only in the second half of the twentieth century did Canadian choral music

\footnotetext{
${ }^{36}$ Ibid., 17-18.

37 Ibid., 222.

${ }^{38}$ Canada. Royal Commission on National Development in the Arts, Letters and Sciences, Report of the Royal Commission on National Development in the Arts, Letters and Sciences (Ottawa: King's Printer, 1951), 19.

39 Nick Strimple, Choral Music in the Twentieth Century (New Jersey: Amadeus Press, 2002), 275-277. ${ }^{40} \mathrm{lbid}$.
} 
composers such as R. Murray Schafer, John Beckwith, Imant Raminsh, Stephen Chatman, and Srul Irving Glick begin to diverge from this tradition. Still, the liturgical choral music tradition continues in the work of composers such as Ruth Watson Henderson, Barrie Cabena, and Derek Healey.

The emphasis here on the English liturgical tradition should not be interpreted as undervaluing the tremendous work of francophone, Black, and female composers in the broader history of Canadian choral music. Figures such as Guillaume Couture, Jean Coulthard, Violet Archer, Gabriel Charpentier, Nathaniel Dett, André Prévost, and Nancy Telfer deserve mention and demonstrate the diversity of the field. ${ }^{41}$ That said, the English liturgical tradition was a dominant influence upon choral music from the early- to mid-twentieth century.

Despite its prominence in Canadian cultural life, choral music barely registered in the processes that developed federal cultural policy in Canada after the Second World War. They originated in planning for a better postwar world that would justify wartime sacrifices, a project known at the time as "Reconstruction." At the Kingston Conference of Artists in 1941, the arts community gathered to discuss its marginal status in Canadian society. It pointed to United States' government's role in supporting artists through the Works Progress Administration as part of Roosevelt's New Deal. ${ }^{42}$ Tippett writes of the importance of the Kingston Conference, noting Vancouver artist Jack Shadbolt's claim that "it was the first time that Canadian artists right across the country achieved any sense of social identity." ${ }^{43}$ Conference members recommended a variety

\footnotetext{
${ }^{41}$ Ibid., 275-280.

42 Litt, The Muses, 22.

43 Tippett, Making Culture, 165.
} 
of measures to support art and artists, including research on the economic status of the artist. From this Conference emerged the Federation of Canadian Artists, which quickly emerged as "the country's visual artists' most powerful lobby group." 44 Later, the initial public hearings of the Massey Commission featured arts organizations such as the Dominion Drama Festival, the Canadian Writers' Foundation, and the Royal Society of Canada. The Federation of Canadian Artists distributed over five hundred copies of its brief to its branches, other arts and cultural organizations, and the press. A coalescing culture lobby was asserting its influence, turning the Massey Commission "into something of a national crusade" for government action in cultural affairs. ${ }^{45}$ Choirs and choral music organizations were hard to find in this lobbying effort. Among the many associations and organizations that submitted briefs and appeared before the Massey Commission, choral music was represented only occasionally or tangentially by groups such as the Bellman Male Chorus, Church of England in Canada, Conservatoire Populaire et le Choeur de France, and the Sir Ernest MacMillan Fine Arts Club. ${ }^{46}$ In subsequent years, choirs and choristers continued to be relatively inactive in lobbying and overlooked in major developments in the broader field of the arts. When they did appear in such efforts, it was as a part of a larger group of musical interests. The Royal Canadian College of Organists continued to operate, as did the Federation of Canadian Music Festivals, and the ambit of each intersected with the field of choral music. In 1951, a group of composers, including some who worked in choral music, such as Srul Irving Glick, launched the Canadian League of Composers. The

\footnotetext{
44 Ibid., 165-166.

${ }^{45}$ Litt, The Muses, 48-55.

${ }^{46}$ Canada. Royal Commission on National Development in the Arts, Letters and Sciences, Report of the Royal Commission, 424-431.
} 
Composers, Authors, and Publishers Association of Canada, an active industry association, and the Canadian Music Centre, included musicians involved in choir work. ${ }^{47}$ In 1969 one observer claimed that most professional musicians in Canada belonged to the American Federation of Musicians of the United States and Canada, but this seems unlikely and, as will be discussed later in this paper, is most certainly not true today. ${ }^{48}$

Not only were choirs and choristers missing in action, but the direction set for cultural policy by the Massey Commission held little promise for them. As organizations rooted in local community culture, their interests lay in policy that addressed talent and capacity development at that level. A coalition of artists that appeared before a 1944 parliamentary committee, the Turgeon Committee on Reconstruction and Reestablishment, advocated for government aid to the arts in order to solve questions of both an uncultured populace and underemployed artists. ${ }^{49}$ Building on the deliberations at the Kingston Conference three years earlier, it recommended that the federal government fund community centres as war memorials. It envisioned these centres as local hothouses for developing artists and showcasing their work at the grassroots level. They would include a theatre and movie projector, an art gallery, a library, and space for classes and workshops. ${ }^{50}$ The Turgeon committee reacted positively to the artists' proposal. As Tippett put it:

Here was a plan which served the amateur and the professional; which made the municipal, provincial, and federal governments financially responsible for culture; and which addressed the problems created by central Canadian domination, the

\footnotetext{
${ }^{47}$ Keith MacMillan, "National Organizations," in Aspects of Music in Canada, ed. by Arnold Walter (Toronto: University of Toronto Press, 1969), 301-303.

48 Ibid., 306.

${ }^{49}$ Litt, The Muses, 23.

${ }^{50}$ Dot Tuer, Mining the Media Archive (Toronto: YYZ Books, 2005), 102.
} 
country's vast size, and its reliance upon foreign cultural producers, organizers, and philanthropists. ${ }^{51}$

The community centre proposal had significant potential to benefit choirs. It would give them venues outside of local churches for training, rehearsal and performance where choristers could mix and mingle with artists from other disciplines and find mutual interests and inspiration.

As it turned out, federal cultural policy went in a different direction. Minister of Defense Brooke Claxton wanted the federal government to take action on culture to defuse proposals being put forward by the increasingly popular Co-operative Commonwealth Federation. Claxton urged Prime Minister Louis St Laurent to consider the political gains to be made by catering to an educated leadership class, or as Litt puts it, the "cultural elite," and a rising tide of postwar nationalism. While direct aid to artists did not have significant political support, Claxton proposed the establishment of a royal commission to investigate the possibility of federal funding for the arts mixed in with a number of other politically sensitive issues. This culminated in 1949 with the formation of the Massey Commission to study government cultural institutions and policies, Canada's international cultural relations and related matters. ${ }^{52}$

The decision to launch a royal commission was a turning point in the federal cultural policy discussion in Canada. The Massey Commission was disposed to deliver a centralized response to the policy problems raised by cultural nationalism, fears of American cultural imperialism, and the plight of individual artists. Its response to the perceived threat of an invasive mass culture driven by American cultural industries was

51 Tippett, Making Culture, 173.

52 Litt, The Muses, 24-30. 
to create national cultural institutions. This response was not well aligned with the decentralised form of support for the arts advocated for by national artists' groups. The policy trajectory initiated by the Massey Commission remains with us to this day.

In his history of Canadian cultural policy, Ryan Edwardson describes the Massey commissioners as "nationalistic culturalists seeking highbrow Canadian content as a counterweight to the abundance of socially corrosive entertainments." ${ }^{3}$ In the context of the colony-to-nation transition and in the midst of rapid evolution in communication and technology, Masseyites believed the government should be cultivating a learned and enlightened population, protected from the temptations of the un-Canadian and unedifying mass culture propagated by Canada's southern neighbour. ${ }^{54}$ The preamble of the commission's report declared:

$\ldots$ it is in the national interest to give encouragement to institutions which express national feeling, promote common understanding and add to the variety and richness of Canadian life, rural as well as urban. ${ }^{55}$

The report referred to the need to create and support opportunities for workers in the arts, letter and sciences, and commented that one measure of a civilisation is the degree to which these artists are "supported, encouraged and esteemed by the nation as a whole." ${ }^{56}$ The nationalistic goals of cultural policy in the era of Masseyism were tied to the development of the Canadian nation through the fostering and encouragement of highbrow art and artists.

\footnotetext{
${ }^{53}$ Ryan Edwardson, Canadian Content: Culture and the Quest for Nationhood (Toronto: University of Toronto Press, 2008), 10.

54 Ibid.

${ }^{55}$ Canada, Report of the Royal Commission, xvii.

${ }^{56}$ Ibid., 9, 182.
} 
The upshot was a cultural policy to be delivered through existing national institutions like the Canadian Broadcasting Corporation and the National Film Board. Direct support for artists would come from a new national institution, the Canada Council for the Arts. First recommended by the Massey Commissioners, though not actually implemented until 1957, the Canada Council for the Arts was given, and continues to wield, a broad mandate "to foster and promote the study and enjoyment of, and the production of works in the arts, humanities, and social sciences." 57 This includes providing grants, scholarships and/or loans to individuals or groups, support for representations of art and scholarly works, and cultural exchanges with other countries through the Canadian Commission for UNESCO.

This model of arts funding followed the lead of Britain and the United States. The funding of the Council was to derive primarily from endowments, as was the case in the United States. ${ }^{58}$ The Canada Council maintained the arm's-length approach to arts funding instituted in the UK, as explained by the Massey Commissioners through the words of John Maynard Keynes, the then Chairman of the Arts Council of Great Britain:

A semi-independent body is provided with modest funds to stimulate, comfort and support any societies or bodies brought together on private or local initiative which are striving with serious purpose and a reasonable prospect of success to present for public enjoyment the arts of drama, music and painting. ... The task of an official body is not to teach or to censor, but to give courage, confidence and opportunity. ${ }^{59}$

\footnotetext{
${ }^{57}$ Canada Council for the Arts Act, Statutes of Canada. 1985.

${ }^{58}$ Monica Gattinger, The Roots of Culture, The Power of Art: The First Sixty Years of the Canada Council for the Arts (Montréal \& Kingston: McGill-Queen's University Press, 2017), 31-33. The French system was also a model, however, its arts council funded not just the arts but also culture in the broader anthropological sense of the term.

59 John Maynard Keynes, as quoted in Canada, Report of the Royal Commission, 375.
} 
Hillman-Chartrand and McCaughey label the British model "the patron state."60 According to these authors, this model's strength is also its greatest weakness: arts councils employ artists themselves to judge the merit of grant proposals. While this approach avoids political interference and adjudicates on the basis of artistic excellence, it can also foster elitism. ${ }^{61}$ This final element in the Canadian model, that of the arm's-length principle, remains a crucial element to artists' support for the Council. The role of the institution is, as Keynes writes, to encourage, not direct culture. In response to a perceived cultural crisis, policy makers designed an institution that balanced liberalism and nationalism. ${ }^{62}$

In sum, the Masseyite era of Canadian cultural policy structured arts funding to resist American mass culture with a Canadian version of highbrow, European art. Artists served, willingly, as a means to this end, and advocated, self-servingly, for government support for their work. The Canada Council, the new institution charged with fulfilling this policy, was designed to shield the government from accusations of limiting freedom of expression or designing culture. It was a far cry from the community centre approach artists had proposed to the Turgeon Committee. Their emphasis on a decentralized, democratized and communal cultural policy had been ignored in favour of one that privileged artistic merit supported by national cultural institutions. Devised in the face of the perceived threat of American mass culture, it mirrored that threat in developing a complex of large-scale institutions to counteract it. It sought to offset the influence of

\footnotetext{
${ }^{60}$ Harry Hillman-Chartrand \& Claire McCaughey, "The Arm's Length Principle and the Arts: An International Perspective - Past, Present and Future," in Who's to Pay for the Arts?, ed. Milton C. Cummings, Jr. and J. Mark Davidson Schuster (New York: American Council for the Arts, 1989), 50. 61 Ibid.

62 Litt, The Muses, 185.
} 
American private entertainment industries and their legions of professional and marketable artists with a state-sponsored Canadian system of publicly supported cultural institutions that would in turn support professional and marketable Canadian artists. This policy trajectory left artists whose practice was based in local, communitybased art forms out of the picture. professional choristers among them. Although they worked in an accessible, popular art form that was deeply embedded in the culture of local communities, choristers would not be well-served by the emerging system of arts subsidies.

In the years following the development of this Masseyite strategy, its shortcomings became increasingly evident. Policy makers in the egalitarian 1960s were influenced by an emergent understanding of Canada as The Peaceable Kingdom, "a socialist-leaning nation of equality, multiculturalism, peacekeeping, and a social-welfare safety net directed to ensuring that all Canadians could benefit from the nation's wealth." ${ }^{63}$ Accordingly, they toned down the elitism of Masseyism. National unity concerns reinforced the perceived need for federal government sponsorship of culture. Cultural policy of this era de-emphasized the elitism of its origins, but as it expanded continued to be characterized by a frame of reference and infrastructure that were national in focus.

Artists in the era of the Peaceable Kingdom became concerned with the distinction between arts in Canada and Canadian arts. Seeing Canadians as British North Americans, nationalists in earlier eras had tended to import British culture to offset continental influences. The new nationalists of the 1960s instead emphasized

${ }^{63}$ Edwardson, Canadian Content, 16, 138, 143. 
Canadianization and promoted emerging indigenous art and artists. Grassroots theatres like Theatre Passe Muraille and the Tarragon Theatre in Toronto opened to present works written by and for the people of Canada. The Canada Council was slow tocatch on. In the $1971-72$ season, it granted thirty-two theatres $\$ 13,000$ per play. A mere eighteen of the subsidized plays were written by Canadians. As it continued to reflect the Masseyite worldview that prioritized European high arts as a national cultural prophylactic, nationalist artists and intellectuals began to question its funding choices. They wanted cultural policy that supported their redefinition of the nation. ${ }^{64}$

Throughout these formative decades in Canadian cultural policy, the choral music scene changed little. Church and school choirs remained numerous. New choirs emerged, most notably Canada's first fully professional ensemble, the Festival Singers, in $1968 .{ }^{65}$ The Mendelssohn Choir, the Disciples de Massenet, and the Elgar Choir of Montreal were producing high quality choral work, regularly collaborating with symphony orchestras. ${ }^{66}$ In its Second Annual Report (1958-59), the Canada Council reported "a large number of choirs in practically every part of the country." It chose to fund those most able to reach large audiences with their concerts. ${ }^{67}$ Notably, these funds were to be "partially earmarked for the use of a professional orchestra, thus giving some additional work to orchestral players." There was no stipulation that they be directed to support professional choristers. ${ }^{68}$ The 1968-69 Annual Report mentioned the aforementioned Festival Singers, noting that "a combination of assistance which

\footnotetext{
64 Ibid., 153-158.

65 Durrell Bowman et al., "Choral Singing: Choirs".

66 Potvin, "Performers," 161.

${ }^{67}$ Canada. Canada Council for the Arts, "Second Annual Report 1958-1959" (Ottawa: Canada Council for the Arts, 1959), 25.

68 Ibid.
} 
includes the Province of Ontario Council for the Arts and the $\mathrm{CBC}$ has made it possible for the Festival Singers of Toronto to go on a professional basis and (they) have high hopes for their future."69 The Canada Council's funding policy reflected the national institutional bias of federal cultural policy. Choirs were funded infrequently, and only when they were deemed to have risen above the lowly status of community cultural organizations and achieved a national reputation. In these infrequent cases the Canada Council prioritized the professionalisation of performers, including, in the case of its 1958-59 report, targeting grants not just to the choirs but orchestra players who were recognized as professionals while the choristers were not.

The 1970s were the dawning of a third era of Canadian cultural policy: cultural industrialism. The continuing threat of French-Canadian nationalism and separatism led to a new policy emphasis on cultural expressions of Canadian identity that could bolster national unity. The federal government was positioned as the "guardian of nationhood," responsible for nurturing a national culture. ${ }^{70}$ The objectives of the Arts and Cultural Policy of 1968 included "to forge national unity," "to stimulate the two founding cultures and to integrate the original contribution of the native peoples and New Canadians," and "to give a cultural dimension to our political and economic democracy and a more democratic dimension to our cultural activities." 71 While this last directive suggested a greater emphasis on grassroots culture, the policy also stated that grants were to be provided only "for purposes that are clearly of national benefit." 72

\footnotetext{
${ }^{69}$ Canada. Canada Council for the Arts, "12th Annual Report" (Ottawa: Canada Council for the Arts, 1969), 16.

${ }^{70}$ Edwardson, Canadian Content, 186-87.

${ }^{71}$ Arts and Culture Policy of 1968 as quoted in Ibid., 195.

72 Ibid.
} 
Industrial and economic precepts were also prevalent. Democratization translated into increased support for the popular arts of the entertainment industries. The new policy era of cultural industrialism relied on subsidizing private cultural industries to produce Canadian content in the cultural genres Canadians consumed through the mass media in the hope that, all else being equal, they would choose domestic over imported fare. ${ }^{73}$ Perversely, these subsidized Canadian producers were accused of creating products that had no identifiable Canadianness so that they could be sold more profitably in the international cultural marketplace. International recognition and demand would be the criteria by which artistic merit was judged. This idea was evident in the words of the Appelbaum-Hébert report (1982):

Canadian artists and their work must be publicized - and marketed - more effectively than they have been in the past. Success in these efforts will stimulate demand for and consumption of the cultural output of the country. ${ }^{74}$

In sum, the cultural industrialist era moved the justification for cultural policy away from nationalist cultural elite's original emphasis on culture that was "good" and "Canadian" towards culture that reinforced federalism or sold well outside as well as within Canada.

For artists themselves, these changes in cultural policy goals meant a shift in the way their art was valued. Cultural policy makers were now concerned about the economic viability of art. The 1983 report Vital Links: Canada's Cultural Industries stated:

While individual writers, artists and performers in the lively arts of the stage are increasingly able to reach their audiences in Canada, the financing of the arts remains as problematic as ever. Still, a judicious mixture of attention from the public and private sectors at all levels, combined with an increase in the marketing and management skills of creators themselves, give us hope for a

\footnotetext{
73 Ibid., 186-187.

${ }^{74}$ Final Report of the Federal Cultural Policy Review Committee, quoted in Jody Berland, "ApplebaumHébert Report," The Canadian Encyclopedia (December 15, 2013).
} 
growing measure of stability in this basic aspect of the cultural environment. ${ }^{75}$ Cultural policy was now guided by industrial precepts. It would subsidize artistic output for which there was demonstrated demand in the marketplace. English-Canadian culture was deemed to be suffering from the lack of a "star system," a key feature driving audience interest in the products of cultural industries elsewhere. This perceived problem led to shifts in programming at the $\mathrm{CBC}$ and the establishment of the MAPL (Music, Artist, Performance and Lyrics) identifiers in the music industry. ${ }^{76}$

Where did choristers fit into this cultural policy scene? In the Canada Council's Annual Report of 1978-19, choral music accounted for four per cent of the funding allotted to music and opera. Orchestras and opera received just short of sixty per cent of that funding. These high-profile performing arts companies were not cultural industries, but the cultural industries approach of rewarding professionals who produced internationally recognized work spilled over into the performing arts sector as well. ${ }^{77}$ In recent decades, the economization of cultural policy has continued, with market share displacing cultural nationalism's original goals of supporting art that was both Canadian and good. Bourcheix-Laporte described the effects of neoliberalism on cultural policy as constituting "an ideological shift in the valorization of culture(;) one that emphasizes culture's potential to bolster economic growth by harnessing the promises of digital and creative economies."78 Creative Canada, Canada's most recent cultural

\footnotetext{
${ }^{75}$ Canada. Department of Communications, Vital Links: Canadian Cultural Industries (Ottawa: Government of Canada, 1987), 7.

${ }^{76}$ Edwardson, Canadian Content, 244.

${ }^{77}$ Canada. Canada Council for the Arts, "The Canada Council 22nd Annual Report 1978-1979" (Ottawa: Canada Council for the Arts, 1979), 13.

${ }^{78}$ Mariane Bourcheix-Laporte, "Creative Canada: A Critical Look at a 'New' Cultural Policy Framework," CRTC, 2019.
} 
policy document, exemplifies this perspective, noting "(O)ur creative industries can be a vital part of our future economic growth and our identity as a country."79 The neoliberal era has coincided with the digital age, and the combination of the two has led to reconceptualization of what constitutes an artist. "Creative workers" are lionized as key players in the "creative economy," a special sector that is deemed to have a magical catalytic effect on economic growth. Richard Florida's creative class thesis argued that the creative class (including workers formerly known as artists) are the drivers of the new creative economy, as creativity itself, which "we clearly understand ... as a source of economic value," resides in the intellectual capital of the creative class. Florida refines his definition of the creative class by describing a "Super-Creative Core" that includes scientists, engineers, professors, poets, novelists, artists, entertainer, actors, designers, architects, and thought leaders and the "creative professionals" who engage in knowledge-intensive industries, like ICT (information and communication technology), finance, health, and business. ${ }^{80}$ Creative Canada is explicit about its inclusion of industries beyond the arts in its definition of creative industries:

In our vision, we move deliberately to using "creative industries" to include a wider range of industries that contribute to the creative sector: design, fashion, architecture, video games, digital media and multiplatform storytelling transmedia. The intent is to recognize their role as employers and producers in the creative economy. ${ }^{81}$

In this broader formulation of creative workers, artists, whose livelihood was ostensibly one of the original concerns of Canadian cultural policy, become just one of legions of

\footnotetext{
${ }^{79}$ Canada. Canadian Heritage, "Creative Canada Policy Framework," (Canada: Canadian Heritage, 2007), 8, 6 .

${ }^{80}$ Richard Florida, The Rise of the Creative Class, Revisited (New York: Basic Books, 2012), 24-25, 3839.

${ }^{81}$ Canada, "Creative Canada," 12.
} 
creative professions. As the Creative Canada promotional materials suggest, Canadian cultural policy makers, while continuing to make reference to broader nationalistic ends, have all but completely shifted the rationale for government funding and the criteria for awarding it to economic factors. The discourse surrounding the shift from cultural industries to creative industries has been well documented, but its effects on artists is still largely unappreciated. The cultural goals that once guided policy making have fallen by the wayside. ${ }^{82}$ For choristers, Canadian cultural policy got off on the wrong foot early in the postwar era, and instead of working its way back to them, continually shifted its focus farther and farther away.

The Canada Council, in this era of neoliberalism, received an influx of support from the newly elected Liberal government in 2015 to the tune of $\$ 550$ million. While this support was most welcomed by the cultural institution, the Creative Canada policy framework insisted that these funds were to support a "new, streamlined and outcomesbased funding model that allows artists, groups and organizations to define their own ambitions and projects with greater flexibility." ${ }^{83}$ The outcomes-based funding model refers to a system in which "programs, initiatives and activities will be measured by the results as they relate to specific outcomes." The outcomes and results must be clearly defined and linked to the inputs, activities and outputs of the Council's programs, initiatives and activities." 84 Indicators, "the specific items of information that track a program's progress on outcomes and/or track progress made towards targets (e.g.,

\footnotetext{
82 See Terry Flew, The Creative Industries: Culture and Policy (London: SAGE Publication Ltd., 2012), 59-82.

${ }^{83}$ Canada, "Creative Canada," 14.

${ }^{84}$ Canada Council for the Arts, "Performance Measurement Policy" (Canada Council for the Arts: Canada, 2007), 7.
} 
artists create work that advances artistic practice; new works are created; a partnership supports the public access to the Canadian arts)" are to be used to determine the extent to which an outcome has been achieved. ${ }^{85}$ This type of evaluation process is similar to broader trends in public sector evaluation (tied to Michael Barber's "deliverology" method), which have previously generated controversy about their effectiveness in delivering social policy reform. ${ }^{86}$

It might fairly be asked how such mind-numbing feats of bureaucratization serve the interests of culture. If, as stated previously, the purpose of the Council is "to foster and promote the study and enjoyment of, and the production of works in the arts, humanities, and social sciences," it seems that it has been drawn far, far away from its original mandate by cultural industries and creative class concepts that valorize economic viability and deliverology performance measures above the individual artist or work of art. ${ }^{87}$

This mismatch is even further evident if we think of professional choristers as artists meriting consideration for cultural subsidy. Of the ten most recent Annual Reports from the Canada Council for the Arts, only one, the 2011-12 Annual Report, mentions choral music in any substantive manner. ${ }^{88}$ The $2019-20$ open data table on grant recipients demonstrates that several choral music organisations received funding from the Canada Council. They included the Toronto Mendelssohn Choir $(\$ 80,000)$, the Nathaniel Dett Chorale $(\$ 75,000)$, The Elora Singers $(\$ 100,000)$, and the Elmer Iseler

\footnotetext{
85 Ibid., 5.

${ }^{86}$ See Lisa Birch and Steven Jacob "Deliverology' and Evaluation: A Tale of Two Worlds," Canadian Journal of Program Evaluation 34 no.2 (2019): 303-28.

87 Canada Council for the Arts Act, Statutes of Canada. 1985.

${ }^{88}$ Canada. Canada Council for the Arts, "2011-2012 Report” (Ottawa: Canada Council for the Arts, 2012), 12.
} 
Singers $(\$ 96,000)$, among others. ${ }^{89}$ These figures are chickenfeed relative to the Canada Council's total budget of about $\$ 350$ million. Moreover, the exceptional choirs it goes to are just the tip of the iceberg when it comes to the total number of choirs and choristers active in Canada. Contextualizing in this way suggests that professional choristers are largely overlooked in Canadian cultural policy. They are lost in the shuffle between an art form that is inherently communal, and lacks clear professional standards and terms, and a governmental policy that prioritizes cultural forms and creative workers who are demonstrably professional and create economic value. It is not the position of this paper that this situation is inherently bad. Professional choristers may be better off hidden and/or misunderstood. That said, contemporary cultural policy's neglect of choristers makes it all the more important to investigate their lived experiences to better understand both the role they play in contemporary Canadian culture and the ways that their misfit status manifests in their work and career challenges.

${ }^{89}$ Canada. Canada Council for the Arts, "Open Data Table 2019-2020" (Ottawa: Canada Council for the Arts, 2020), https://canadacouncil.ca/-/media/Files/CCA/Research/stats-and-stories/data-tables/201920/en/opendatatable2019-20EN.xlsx. 


\section{Chapter Two: The Nature of the Work}

In order to properly understand the type of cultural work performed by a professional chorister, it behooves us to examine in more detail the nature of their art form and the conditions of their work. As alluded to previously, one attraction of singing in a choir, historically and today, is its accessibility. If one has the ability to read music, and sometimes even if not, one can join a choir without any formal training, expensive investment in instruments or coaching, or previous experience. In choirs across the country, these elements describe a reasonable number of choristers in community choirs, church choirs, and other amateur organisations. However, as this section will describe, professional choristers are also embedded in each of these types of communal art making and are often unrecognized as professionals to the unfamiliar eye. As a point of entry into their experiences, this section will outline the organisations and institutions in which professional choristers work. The bottom line is this: as workers in an inherently communal industry, professional choristers are omnipresent in the Canadian cultural scene yet largely hidden from the policy gaze.

To begin, the definition of choir is not as simple as it may seem. According to the Canada Council, choirs fall into the category of music and sound organizations, in which it adjudicates the applications of choirs, orchestras, and opera companies alongside one another. The category is defined as follows:

Music organizations or concert societies (such as orchestras, choirs, incorporated ensembles and opera companies) perform and present the work of musicians, composers and creators that maintain a professional music and sound practice (as defined by the Council).

To be eligible as a music organization or a concert society, you must: 
- have a mandate in music and sound

- be incorporated as a not-for-profit organization in Canada

- have been in operation for a minimum of 2 years

- have a history of at least 2 public performances

- have diversified sources of revenue. ${ }^{90}$

Unlike some other arts councils, the Canada Council does not require a certain number of participants in order to be labeled a choir.

This definition encompasses better known, highly accomplished choirs-the "regular suspects" who were listed as recipients of funding at the end of the last chapter. However, it excludes the vast majority of those organizations, informal or formal, that, for the average Canadian, qualify as a choir. It is worth noting here that the terms choir and choral music organisation are used interchangeably in this piece. Nowhere in the definition of choir, according to the Canada Council for the Arts (which, as discussed above, is a funder of choral music organisations) is there a definition of who qualifies as a professional chorister.

Choral Canada is the industry association and national voice of the Canadian choral community. It represents over 40,000 choral singers and their provincial choral music associations across the country. ${ }^{91}$ In 2017 , Choral Canada published its National Choral Census report, articulating the substantial contribution choral music makes to Canada's cultural life. According to the report, just short of one in four children (people under the age of eighteen) sing in choirs, a number that is triple that of the number of children who play hockey, which is known as Canada's game. Approximately 1.8 million Canadian adults (people aged eighteen and older) sing in choirs, whereas only 1.2

\footnotetext{
90 Canada. Canada Council for the Arts, "Applicant Profiles," accessed November 25, 2017, canadacouncil.ca/-/media/Files/CCA/Funding/Grants/ApplicantProfiles_EN.pdf, 133.

${ }^{91}$ Choral Canada, "Home," 2016, http://www.choralcanada.org/.
} 
million Canadians (people aged fifteen and older) play hockey. Even those who do not necessarily sing in choirs themselves engage with choral music in a substantial manner. Over one in four or 7.8 million Canadian adults attended a choral music performance in 2016. ${ }^{92}$ The Ontario-specific statistics mirror this breadth of activity. As of 2011, Choirs Ontario estimated that there are approximately 1.9 million active choral singers in Ontario, or almost one of every seven Ontarians. ${ }^{93}$ These statistics underline the popularity of choral music in Canada.

The Choral Canada report also noted the work that choral music organisations undertake in their communities. Of the 1,541 choirs, choruses, and singing groups who responded to the study, 68 per cent participated in outreach, including singing in hospitals and other community events, 62 per cent participated in charity concerts or singing engagements, and 61 per cent had free concerts or singing engagements. The choral music groups represented were from across the country, from Nanaimo, British Columbia to Halifax, Nova Scotia, and from Cambridge Bay, Nunavut to Yellowknife, Northwest Territories, including at least one from each province and territory. In terms of Canadian content, 88 percent of choirs that participated in the study performed Canadian music in their last season, and 34 per cent of choirs commissioned a Canadian piece in the last year..$^{94}$ In sum, choral music communities engage a significant portion of the Canadian population right across the country, participate in building communities, and help develop Canadian art.

\footnotetext{
92 Choral Canada, "National Choral Census" (Toronto: Choral Canada, 2017), 2-3.

${ }^{93}$ Choirs Ontario, "Ontario Choir Profile" (Toronto: Choirs Ontario, 2011), http://www.choirsontario.org/downloads/2011 Choral Data Study - Final.pdf, 1.

${ }^{94}$ Choral Canada, "National Choral Census," 8-10.
} 
The Choral Canada study found that, of eligible respondents, the average annual operating revenue of a choir is $\$ 14,000$. This budget is derived, on average, from the following sources: $52 \%$ earned (ticket sales, recordings), $24 \%$ from the private sector, $17 \%$ from government, and $7 \%$ from other sources. ${ }^{95}$ The Choirs Ontario, Ontario Choral Profile, from 2011 demonstrates even less reliance on government funding with a mere $6 \%$ of average operating budgets emanating from government sources. Of the choirs interviewed for this study, only $10 \%$ received funding from the federal government, with $5 \%$ having applied and not received any. This compares poorly to lower level of governments with greater presence in the funding models: $28 \%$ of choirs received provincial funding, and a further $7 \%$ applied and did not receive any. $32 \%$ of choirs received municipal funding, along with a further $9 \%$ who applied and did not receive any. Notably, the Choirs Ontario study found that professional and semiprofessional choirs were significantly more likely than amateur choirs to have received external funding ( $83 \%$ vs. $52 \%$, respectively). ${ }^{96}$

This funding discrepancy matches the narrative of this paper: choral music, as an art form, is intuitively communal and predominantly amateur, thereby mismatching with a federal arts funding model which prioritizes professionalization and economic indicators of excellence. When federal government funding is secured, as rare as it may be, it is far likelier to go to groups with the prioritized qualities. Yet it is abundantly clear that choral music is a popular cultural practice deeply integrated into Canadian and Ontarian society. As subsequent sections will demonstrate, it is also clear that professional choristers work each and every day with community organizations as

\footnotetext{
95 lbid.

${ }^{96}$ Choirs Ontario, "Ontario Choir Profile," 28-29.
} 
cultural creators in an art form that is unsupported by the cultural policy system. The following sections of this chapter will discuss a typology of choirs in which these creators work.

\section{a. Professional Choirs}

As discussed above, Canada's first ever fully professional choir was the Festival Singers, which first performed in 1968. Since then, professional choirs have provided part of the regular work of professional choristers. Choirs that fall into this category employ choristers in a secular setting. Unlike choirs that include volunteers, including auditioned volunteer choirs, professional choirs are made up solely of paid singers. Professional choirs are often chamber choirs, a term commonly used to describe music played in small groups, often with as few as one chorister per part. The expectations in performances and rehearsals of these organisations are high. They have few rehearsals and more difficult music while demanding consistent accuracy in tone production, consonant placement, volume, and collaboration.${ }^{97}$ Chanan paraphrases Adorno in describing chamber music as involving an ethic of courtesy in which each musician exercises "reflective self-containment" in listening to others and collaborating towards a common goal. ${ }^{98} \mathrm{~A}$ professional choir expects its choristers to practice courtesy in an effort to create a collaborative environment conducive to a balanced performance.

\footnotetext{
97 Interview - Bass, April 2020, 3.

98 Michael Chanan, Musica Practica: The Social Practice of Western Music from Gregorian Chant to Postmodernism (New York: Verso, 1994), 49.
} 
Toronto is home to a disproportionate number of the professional choirs that benefit from government funding. They include The Elora Singers, the Elmer Iseler Singers, the Tafelmusik Chamber Choir, Choir 21, Aspirare, the Nathaniel Dett Chorale, and Opus 8. Professional choristers will often sing in multiple professional choirs. One alto describes their work as "scaffold(ing) in a variety of ... groups, both professional and volunteer." 99 Indeed, for many professional choristers, having a long-term contract with a professional choir is an enviable position to be in. Work is still unstable, however, because scheduling conflicts require organizations to bring in substitute performers on a regular basis. There is a limited pool of musicians capable of filling in. One of the crucial considerations for a professional choir is reproducing courtesy with changing personnel in order to be able to continue creating music at a high level. Often, they must choose between hiring a singer of exceptional quality who is in high demand, or a slightly inferior performer whose availability can be counted on.

An eloquent description of the expectations of a professional chorister in a professional choir come from a soprano who tells a humorous and revealing anecdote about one of her first gigs as a professional singer in Toronto:

I auditioned for the Nathaniel Dett Chorale and the Elora Festival in one week. I think they were back-to-back auditions. The Dett Chorale actually called me back first, because they were going on a tour and they had had somebody drop out. So, it was like, do you want to come on a 26 -day tour with us... tomorrow? I was like, um okay.

So, my first professional choral experience was a giant tour with the Nathaniel Dett Chorale. It was trial by fire, especially because they do a lot of their rep memorized. At the time, they didn't plan their concert rep. It would be like; you take every rep we have ever sung on stage with you and the conductor will announce from the stage what we're going to sing next. (That was) essentially how they operated back then.

99 Interview - Alto, May 2020, 3. 
I remember we were in Calgary, and we were going to be on Breakfast Television Calgary the next morning. Nobody knew what we were going to sing. The rumour mill started through the hotel that we were going to sing this piece that was in Swahili that had been taught to them by rote by a member of the choir who was from Nigeria who had written it. It had choreography.

I was like, what? And we're going to do this on television?

And so, a bunch of people, we met in the hot tub and rehearsed this piece over and over until 1 in the morning until I knew it. Then sure enough, the next morning, the conductor was like, yep, we're singing this song. And so, I sang the song, by memory, in Swahili, with choreography, on television at 5 am the next morning. ${ }^{100}$

While this chorister's initiation by immersion was not typical, her experience was not as uncommon as one might think. In my professional work I have been asked to sing a piece, live in concert, reading the score in the folder of the person next to me, having never done so previously. In a professional choir with professional choristers, this practice is neither common nor acceptable. Yet it happens, made possible by the technical skill of the musicians on hand.

As a category of cultural work accepted in much of the western world, rewarded internationally at such events as the Grammys, and even occasionally found on popular radio through such groups as Pentatonix, the professional choir meets the criteria for professionalization and economic viability as prescribed by the federal cultural policy framework. As the remaining categories of professional choral work will demonstrate, however, the professional choir provides only a portion of the income stream required for a professional chorister to make a living through their art.

100 Interview - Soprano, May 2020, 2-3. 


\section{b. Religious Organizations}

Earlier in this paper, I discussed the role that religious and liturgical traditions have played in the emergence of choirs in Canada. The legacies of both the French and

English traditions are evident in the work of professional choral musicians in and around

Toronto today. The British liturgical tradition of choral music remains strong in the

Anglican Church of Canada. ${ }^{101}$ Research into this tradition in Canada is limited, but

professional choristers are aware of it because they encounter it from early in their

careers. One of my interviewees reflected on how that tradition changed with the times

in Anglican churches in the late twentieth century:

Around about 1990, cathedrals in England started introducing girls' choirs to the mix, and I was very lucky, here in Toronto, to grow up at Grace Church on the Hill. They were ahead of the curve, the English curve. It's an Anglican church so it's the English choral tradition, but they started in the ' $80 \mathrm{~s}$. So, by the time I joined in January of ' 94 , the girls' choir was thriving. They had about 30 girls, and it was a very strong group. I had older girls to look up to. Occasionally, we got to sing with the men, got to sing that more traditional, four-part soprano/alto/tenor/ bass repertoire. As I mentioned earlier, when I started singing with the boys' choir, I got much more of that.

There were a number of those types of choirs when I was young. I think at least three in Toronto, that I can think of off the top of my head, maybe four. I know that there was, perhaps is, probably was, one in Kingston, Ontario, a couple in Ottawa. I'm not sure elsewhere in Canada, but certainly here, in Toronto, that tradition has pretty much died. There are a few (religious) children's choirs left, but the ones I know about, maybe they have ten kids. They're certainly not the huge, thriving groups that they were when I was a child. Certainly, the men and boys' choir tradition; that has very much died away here. There are no men and boys' choirs left in Toronto, in that vein. There is of course St. Michael's Choir

101 See Alan Mould, The English Chorister (New York: Continuum Books, 2007). 
School, but that's a little bit different in that their back row singers are students themselves. They don't have older men, mature voices. ${ }^{102}$

Folkins (2020) and Pepinster (2017) have written on the apparent growth in church attendance due to primarily musical services such as Choral Evensong. The Church of England's 2018 statistics recorded a 34\% increase over ten years in attendance at weekday services, including Evensong. This suggests that the English cathedral tradition will continue to have a presence in the Canadian choral music scene. ${ }^{103}$

On occasion, a high-end church choir resembles a professional choir, albeit one functioning in a religious setting. One bass describes his experience in a fully professional church choir:

If you end up in the likes of what we'll call the immediate past framework at St. James Cathedral, or, for that matter, the (Toronto) Oratory (at Holy Family Parish in Toronto), you are singing with a core group of fully professional singers. You are expected to blend as a unit. You are expected to be able to read music as flawlessly as possible, but also understand things like dynamics, understand things like phrasing and things like that. It's very second nature. ${ }^{104}$

This description echoes the courtesy ethic of the professional choir in a secular setting.

Such elite church choirs are, however, exceptional. Professional choristers working in the church sector most often sing with a choir composed primarily of amateur volunteers. A soprano describes her experience:

...(I)n many cases, it's a situation where you go and sing as part of their amateur Sunday church choir. They usually rehearse on Thursday evenings and then they sing the service on Sunday morning. And, so you're singing the church music as well as an anthem or two, and then lead the singing of the hymns.

As a section leader or a soloist or whatever term you want to use to cover what the pros do, you are there in order to bolster the section and lead them in terms

\footnotetext{
102 Interview - Soprano, April 2020, 4-5.

103 The Church of England, "Record Numbers of Visitors and Worshippers Flock to England's Cathedrals," The Church of England, November 26, 2019, https://www.churchofengland.org/news-andmedia/news-and-statements/record-numbers-visitors-and-worshippers-flock-englands.

${ }^{104}$ Interview - Bass, April 2020, 3-4.
} 
of getting the right notes but also modelling the sound that is wanted, modelling all of the musical decisions that the conductor has made. ${ }^{105}$

A bass puts it differently:

You would be there as a leader, as a mentor for the other singers. As somebody who is comfortable sight-reading, comfortably singing out and leading the other people in your section, for me, it was the case of the basses. I would sing. There were a lot of other guys, and I would say that they had as much or more musical experience singing in choirs as I did. But, at the same time, they weren't confident the way that I was, as a music student at the time. ${ }^{106}$

In an amateur church choir, paid professional choristers act as leaders of their voice section, as what is known as section leads. They provide a foundation of sound to each section, upon which the volunteer singers rely and build. An alto elaborates on this aspect of being a paid lead in a church choir:

The idea is that you have these stronger leaders, hence leads, who are going to be able to lead their section. They create the tonal centre for it. They make sure that they're within the right pitch, the right rhythm. ...

It guarantees you that you have at least a quartet, depending on the church. Many churches will have a quartet: a soprano, alto, tenor and bass. Some will have more in certain sections depending on the type of repertoire that they do. It also allows the church to then have built-in soloists. ${ }^{107}$

All of these interviewees point to the necessity of the paid lead playing a leadership role.

A bass comments, somewhat less diplomatically:

When it comes to a typical church job in the city of Toronto or surrounding, the role effectively is intended to be that you lead your section of amateur singers, with you being the seasoned, experienced professional. What it usually ends up becoming is you drowning out your section by being the loudest in the room and just making sure that no one else can be heard but you, because you are the one that knows what you're doing. ${ }^{108}$

\footnotetext{
105 Interview - Soprano, April 2020, 3.

106 Interview - Bass, April 2020, 2.

107 Interview - Alto, April 2020, 4-5.

108 Interview - Bass, April 2020, 6.
} 
Additionally, while a music director may not always be able to count on all volunteers to be present each week of the year, paid leads assure each voice part is covered. This is perhaps an undervalued component of the work of a paid lead: by guaranteeing the presence of each voice part, a music director can plan repertoire consistently, and avoid the rush and panic of a Sunday morning without the requisite performers present. In sum, the work of a professional chorister in an amateur choir centres on stabilizing and elevating the performance level of the group.

It is notable that no interviewee referred to any responsibility of the professional chorister in a liturgical setting to offer any kind of religious leadership. Although many work in the Anglican choral tradition, professional choristers also work for other religious traditions - Presbyterian, United, Catholic, Basilian, Episcopalian, Jewish, among others. ${ }^{109}$ Although professional choristers are not explicitly asked to convey religiosity in their work, presumably that is the intent of the repertoire they deliver. Yet their professional status is hidden from the public eye. One alto explains:

Not every church is necessarily open to the idea of having leads. Some churches will hide the fact that they have leads which is something that I find both interesting and hilarious.

Because I find it very strange. For example, I have a friend who attends a church. That church is a Catholic church. Within a lot of the Catholic tradition, this idea of paying for singers is unheard of. And so, within their church, they feel that the idea of paying for singers is unheard of. ${ }^{110}$

The reasons for this deception are interesting to contemplate. Hiring mercenaries may seem like a violation of the pious virtues of religious life. In any event, covering up this

\footnotetext{
109 Interview - Tenor, May 2020, 1.

110 Interview - Alto, April 2020, 4-5.
} 
fact contributes to the anonymity of professional choristers in the broader arts scene, including their low profile in the cultural funding landscape.

Despite its hidden nature, the work of a paid lead in a church choir offers regular work. It is an entry-level job that gives emerging singers access to a professional career. One bass comments:

Particularly as a vocal student, there are all sorts of opportunities for young people, many of whom will go on to have fantastic solo careers. But, while they're at school, it's kind of nice to get paid to sing. So, one of the main staples, I would say, for a young singer, is to be a professional lead in an otherwise voluntary church choir. ${ }^{111}$

It is also one of the more dependable forms of employment for choristers. An alto explains:

I think some of the most regular employment for choral singers would be in the form of a weekly church gig. That can really add some much-needed stability to the job, some regularity, some consistent pay, some consistent work. ${ }^{112}$

Another alto refers to the colloquial term choristers use for the typical rehearsal schedule in church choirs across Canada:

Thursday is choir night in Canada. ... It happens at different times for different churches. Some churches arrange their rehearsal times in a way that permits you to rehearse at different churches over the course of the evening. You rehearse music at the church for the Sunday service following that Thursday, usually, or for whatever upcoming thing. Most churches I know, with very few exceptions, have a rehearsal of Thursday evenings for their choirs. ${ }^{113}$

Indeed, the proverbial "choir night in Canada," or Thursday nights throughout the academic year (September through June) is widely understood as reserved for church choir rehearsals. This regularity is crucial for singers: for relatively minimal work, a professional chorister can rely upon weekly work for at least ten months a year, thereby

\footnotetext{
111 Interview - Bass, May 2020, 3.

112 Interview - Alto, May 2020, 3.

113 Interview - Alto, May 2020, 3.
} 
allowing them to budget and plan from a firm baseline regardless of what other opportunities may arise.

Aside from the stability offered by this work, it has the added benefit of being easy money. As a soprano explains:

I think, a lot of times, depending on the church and depending on where it is, they want you to use your soloist voice, in that context. It's easy-ish money, generally it's pretty basic music. It's something that's widely accepted - I don't know why among people to do. They're pretty easy to get. ${ }^{114}$

The difficulty level of these opportunities, especially ones as a section lead, is relatively low in comparison to the demands of singing in a professional choir, both in terms of the repertoire chosen and the technical skills required.

In sum, gigs with religious organisations are among the most common for professional choristers. They offer both their entry into paid work in singing and a steady income throughout what can be a relatively precarious career. The widely accepted recognition of choir night in Canada is a direct result of the sheer number of professional choristers who engage in work with religious organisations. This said, these employers of choristers do not showcase their professionalism, and thereby contribute to their obscurity. Despite their prevalence, professional choristers working religious gigs remain hidden from the public eye.

c. Community Choirs/Choral Society - the Section Lead or Professional Core

114 Interview - Soprano, April 2020, 4. 
Community choirs offer professional choristers gigs similar to those discussed above. ${ }^{115}$ Symphonic and highly-skilled ensembles such as the Orpheus Choir of Toronto, the Toronto Mendelssohn Choir, the Toronto Chamber Choir, and the Amadeus Choir began as this type of community-based secular choir. The professional chorister often works for a community choir as section lead, participating in all rehearsals and acting as an anchor for the volunteer singers as they learn and perform music. These choirs require paid choristers to maintain professional standards of decorum, musicianship/ musicality, and leadership. On occasion, section leads are asked to organise and lead their own rehearsals, called sectionals, which involve solely the singers of the same voice part across the choir. Depending on the organization and circumstances, leads may be asked to arrange vocal warm-ups in advance of performances and rehearsals, step out of the choir to serve as soloists or for demonstration purposes, and report back to the artistic director on their section's growth and abilities. On occasion, such as in the example of the Toronto Mendelssohn Choir, the group of professional choristers who act as section leads are referred to as the "professional core," often members of a professional choir whose conductor also leads the community choir. ${ }^{116}$

Work as a section lead can be both musically and intellectually stimulating and emotionally and physically draining. For a professional chorister, the tedious work of note-bashing, or learning the notes for a given piece through bashing through them over an extended period of time, even though they had learned the correct melody on the first attempt, can be exhausting. However, when a choir such as the Toronto

\footnotetext{
115 Interview - Soprano, April 2020, 3.

116 Toronto Mendelssohn Choir, "Who We Are | TORONTO MENDELSSOHN CHOIR," 2017, https://www.tmchoir.org/who-we-are/ and Interview - Bass, May 2020, 2.
} 
Mendelssohn Choir has the opportunity to work with an organization like the Toronto Symphony Orchestra in mounting a major, symphonic work with choir such as Ralph Vaughan Williams' A Sea Symphony or Maurice Ravel's Daphnis et Chloe, this hard work is rewarded with unparalleled musical experiences. One bass describes the work of a section lead in a community choir:

So, you're there to provide leadership with the mainly amateur ensemble. But, the standard of the amateur chorister in those groups is really high. Most of them are quite good readers, they know the repertoire. So, it's not like working in a fully professional ensemble, but it's pretty close.

He added that there is also a social aspect to these groups that can be a lot of fun. ${ }^{117}$ While the work can be demanding, it is also rewarding because groups like the Toronto Mendelssohn Choir and the Amadeus Singers are auditioned community choirs composed of talented volunteers dedicated to their craft. An alto describes the Toronto Chamber Choir, for example, as "an advanced amateur choir." 118 Finally, a crucial element of singing in choirs is the opportunity for community and sociability to which the bass quoted above referred. This has been true historically and it remains part of what makes professional choristers' careers fulfilling.

Despite the positive aspects of working with community choirs, it is not necessarily preferred by all professional choristers. One alto describes their logic:

Personally, I never choose large choirs. My reason for that is because I have to feel like my voice matters. So, if I'm singing in a choir that is as big as say the Toronto Mendelssohn Choir, I don't feel challenged if I stop singing and it doesn't make a lick of difference. It has to make a difference. I have to be an integral part of the sound.

\footnotetext{
117 Interview - Bass, May 2020, 2.

118 Interview - Alto, May 2020, 3
} 
My choice has always been smaller groups, chamber choirs. So, things like, well I used to, years ago, sing with the Elmer Iseler Singers, now with The Elora Singers, Les Violons du Roy. ${ }^{119}$

Community choirs are often large, symphonic organisations with over one hundred singers. ${ }^{120}$ Groups of this size can undertake large scale pieces, such as the aforementioned work with the Toronto Symphony Orchestra, that a chamber ensemble could not attempt. Still, as we have seen, this type of work is not for everyone.

Professional choristers' work with community choirs is, once again, largely invisible to the public eye. The collective nature of choral work contributes to this anonymity. Concerns that professionalism might taint the spirit of amateur voluntarism further contribute to their obscurity. While professional choristers as section leads play an integral role in the development and performances of these ensembles, the nature of the art form obscures their contributions. It is not surprising that they get overlooked in a policy environment that prioritizes professionalism and excellence.

Although the nature of their repertoire is different, community choirs employ professional choristers in the same way religious organizations do. Work as a section lead is common. There are opportunities for rewarding experiences singing symphonic music with talented amateur singers and full orchestras, mixed in with less enjoyable moments of note-bashing and tedious rehearsals. Contracts with community choirs are reliable sources of income in a precarious line of work. Yet even in the most prestigious and best-funded community choirs, the contributions of professional choristers, though highly valued by the organization, are largely invisible to the public eye.

\footnotetext{
119 Interview - Alto, May 2020, 2

120 Toronto Mendelssohn Choir, "Who We Are," 2017.
} 


\section{d. The Ad Hoc Gig - Weddings, Funerals, Events}

The final category of gig for a professional chorister is the ad hoc event. A soprano describes these types of ad hoc events:

You might also get paid to do one-off gigs. For example, a wedding: somebody wants a choir at their wedding and so they pull together a certain number of voices. You come in and you may have a rehearsal. Hopefully, you have a rehearsal. Then, you do the church service, or a funeral, or whatnot. ${ }^{121}$

This type of work often takes place in religious settings, where a professional chorister is called upon to perform at a rite such as a wedding or funeral. These gigs often entail a flat fee with little to no rehearsal time, requiring the professional chorister to be able to sight-read and perform as best they can in the time available if the repertoire is unfamiliar.

Ad hoc gigs also emerge on a seasonal basis. As one alto describes:

It was great that way. You could do CBC recordings. At Christmas time, there were also carolling gigs to do where you go out with a quartet and you sing in a mall or something like that. Weddings. Funerals. ${ }^{122}$

Carolling is a staple of popular culture, romanticized in festive season films or antimodern invocations of virtuous community life in days of yore, that generates work for professional choristers year in and year out. These gigs are similar to funerals and weddings in that they involve flat fees and high expectations of sight-reading, although most often the repertoire is familiar and not particularly challenging. Carolling work is made available through professional networks with connections to corporate special

\footnotetext{
121 Interview - Soprano, April 2020, 3.

122 Interview - Alto, April 2020, 3.
} 
events planners, apartment rental companies, or shopping malls that hire singers to be present at festive events.

Another version of the ad hoc contract mentioned by the alto quoted above, CBC recordings, bears further explanation. She goes on to discuss her relationship with ACTRA, the Alliance of Canadian Cinema, Television and Radio Artists:

Thinking back to that time, there was a fair bit of CBC work going on. That's when I got my ACTRA card. So, if you could sight-read and had a decent voice, you could pretty much count on getting called by the guys who put together ad hoc choirs to do various $\mathrm{CBC}$ recordings. There were several shows that would do that. I think the requirements for getting an ACTRA card are probably the same today: you have to do six gigs within two years. I think I was able to do that within three months. ... ${ }^{123}$

Indeed, starting in 1945 and continuing until budget cuts in 1991 prevented further performances and recordings, the CBC regularly employed professional choristers.

The CBC's international service, known as Radio Canada International (RCI) from 1972 on, was an occasional employer of professional choirs. ${ }^{124}$ Kieser refers to the Elmer Iseler Singers and the Toronto Mendelssohn Choir (both conducted by Elmer Iseler at the time) getting $\mathrm{RCl}$ work in 1984 as part of an effort to promote Canadian musical talent around the world. ${ }^{125}$ Recordings made through this process were not insignificant internationally, as demonstrated by arts critic Howard Klein's remarks regarding the albums produced for Canada's centennial, entitled Music and Musicians of Canada:

While it cannot be said that the Centennial issue established Canada as the world center of the 20th-century composition, it goes a long way to putting the

\footnotetext{
${ }^{123}$ Interview - Alto, April 2020, 3.

${ }^{124}$ Durrell Bowman and Gilles Potvin, "CBC Recordings | The Canadian Encyclopedia," in The Canadian Encyclopedia (2015), https://www.thecanadianencyclopedia.ca/en/article/cbc-recordings-emc.

${ }^{125}$ Karen Kieser, "CBC Radio and Canadian Music Abroad," in Hello Out There! Canada's New Music in the World 1950-85, ed. by John Beckwith and Dorith R. Cooper (Toronto: Institute for Canadian Music, 1988), 15-16.
} 
country firmly on the musical map as a major power. ... It is more a reflection of the provincialism of a New York music critic than the obscurity of Canadian composers to comment that I had no idea Canada has produced such a wide range of composers such as are heard on these recordings, or that the styles represented would show the composers to be quite so important. ... This huge project is unparalleled in the contemporary field. ... For Canada to have bestowed such states upon her composers as to have officially recognized their work in this series shows a musical awareness of major importance. ${ }^{126}$

Klein also refers specifically to the work of choral musicians through the "CBC Toronto Chorus," which, along with the Symphony Orchestra and soprano, Mary Morrison, "throws in just about every effect and style now in vogue and ends up sounding superficial and facile." 127 Though, according to Potvin in 1988 , a mere $0.3 \%$ of the $\$ 16.1$ million annual budget by Radio Canada International went directly to musicians, these ad hoc contracts provided for ACTRA job protection and pay rates. ${ }^{128}$

These examples draw attention to the federal government broadcasting policy's potential for supporting professional choristers. It is a source of support worth keeping in mind in future policymaking. They also raise the issue of unionization as a means of addressing professional choristers' precarious employment status. Since these broadcasting contracts dried up, choristers have not had any significant involvement with the labour movement.

Finally, one would be remiss in a discussion of the types of ad hoc professional choral work not to mention the proverbial "ringer" brought in at the last minute to participate in any of the gigs mentioned throughout this section. An alto explains:

\footnotetext{
${ }^{126}$ Howard Klein, "You Can Stay Home and Still Hear the Music of Canada," New York Times (New York), 1967.

127 Ibid.

128 Gilles Potvin, "Radio Canada International: The Voice of Canada after Forty Years," in Hello Out There! Canada's New Music in the World 1950-85, ed. by John Beckwith and Dorith R. Cooper (Toronto: Institute for Canadian Music, 1988), 61.
} 
Ringers are basically people that you hire, often at the last minute, who are pros to beef up your sound. You know that they are going to know the notes. You know that they're going to come in confidently. You know that you can trust them to do their job because it is their job.

So, some amateur organisations will, say within the last three rehearsals, the full rehearsal, the dress rehearsal, and then the concert, will have people who come in because they don't have the budget to have them for the duration of the rehearsal process. But, they'll bring them in for those final two or three so that they can have that additional sound.

You can also give a certain comfort level to your amateur because when they hear this confident sound around them, they know that they're on the right track and it gives them the confidence to then sing out and in some cases to really enjoy the experience more, because they're not concerned. A certain amount of the pressure in terms of getting it right is no longer on them. They can ride that wave as opposed to trying to make the wave. ${ }^{129}$

Indeed, professional ensembles, religious organisations, community choirs, and other ad hoc groups will regularly hire professional choristers for limited term contracts to serve as "ringers" in their choirs. These choristers are often, but not always, hired for the rehearsals that lead into a performance to add an extra, professional voice to their voice section, or cover for a more permanent member who may not be available at that time. This work is inconsistent and irregular, yet common, in that organisations such as the Tallis Choir, the Toronto Mendelssohn Choir, and the choir of St. Basil's Catholic Parish at the University of St. Michael's College regularly seek out professional choristers for these types of gigs. Historically, this work has also been available, but funding for it has not been consistent, as one alto attests:

Of course, there were various chamber choirs around that would hire section leaders or ringers to come in and sing. In those days, the Ontario Arts Council would support church groups who presented concerts and so, there were a lot of concerts at places like Metropolitan United, St. George's United, St. James Cathedral.

${ }^{129}$ Interview - Alto, April 2020, 10. 
But, in their infinite wisdom, they decided that sectarian groups should not be supported by the government, never mind the fact that the money was actually going to the performers. All it did was cut the amount of work we could do. ${ }^{130}$

While the logic of funding criticized above is not at the heart of this paper, the government's reluctance to fund religious groups reduced the ad hoc, ringer-type gigs available to professional choristers. Like the broadcasting policy turn away from recording choirs, it resulted in fewer employment opportunities for professional choristers.

It is important to note that the interviewees quoted above are anomalies among professional choristers in Canada generally because they have more access to work with professional choirs than choristers elsewhere. Of course, choristers are drawn to cities like Toronto which are centres of training and professional community with better work prospects. Such regional disparities must be kept in mind when interpreting the Toronto choral scene. However modest the livelihood of Toronto choristers, relative to Canada as a whole, it likely does not get any better than this.

As we have seen, professional choirs are the primary conduit through which choral culture receives government cultural support. We have also seen that that support is limited compared to the level of subsidy for other arts forms. Moreover, few professional choristers can make a good living from professional choirs alone. We must also keep in mind that professional choristers represent just an elite minority of the millions of Canadians who sing in choirs, and their audiences likewise represent just a fraction of those who listen to choral music.

130 Interview - Alto, April 2020, 3. 
To conclude, in this section, I have attempted to describe the choral music ecosystem through the lens of both broad statistics and a typology of employers of professional choristers. ${ }^{131}$ The choral art form is widespread in Canadian society yet is not awarded cultural funding proportionately. Choirs that are not supported by religious organizations rely heavily on private donations and earned revenue for the bulk of their operating budgets. Professional choristers work in many segments of the choral music ecosystem, including in its professional choirs, religious organisations, community ensembles, and in ad hoc gigs. They are mainstays of an art form ill matched with the federal cultural policy priorities of professionalism and economic viability. The way in which the nature of their work hides them from the public eye exacerbates this situation.

\footnotetext{
${ }^{131}$ Anecdotal evidence suggests that musical theatre may be another source of employment for choristers, especially in the Toronto market. However, none of the choristers interviewed for this study cited musicals as a component of their work. Further research is required to clarify to what extent, if at all, professional choristers are sustained by work in musicals.
} 


\section{Chapter Three: Defining the Professional Chorister}

Having discussed the hidden work embedded in choral organisations of varying types and scopes, we now turn to the work experience of professional choristers. This section is an entry point into debates around who, precisely, qualifies as a professional chorister. It considers some of the characteristics of an individual chorister that qualify them as professional and what or who determines such a judgement. Scholars have written extensively on the nature of work, including that of gig workers in the arts. This section will build on this literature to argue that the fundamental characteristic professional chorister share that distinguishes them from other choristers is that they are paid for their work. We can discuss other characteristics that distinguish them, such as virtuosity, and other ways in which these characteristics are recognized, such as peer recognition, but ultimately the labour market defines their status as professionals. The irony of this definition is that making a living as a chorister is such an iffy proposition.

The literature on this topic shows that it is a venerable scholarly tradition to inquire into the nature of those who perform and comprehend art, and the musical branch of the arts more specifically. Theodor Adorno wrote extensively on the commoditization and fetishization of art (specifically music), differentiating the "advanced product" as one that is original and authentic in opposition to the products of cultural industries which he characterized as a form of "commodity listening." ${ }^{132}$ Adorno claimed that the public value of music lay in its "sensuous magic" and bemoaned that it

\footnotetext{
132 Theodor W. Adorno, The Culture Industry: Selected Essays on Mass Culture, ed. by J.M. Bernstein (London: Routledge, 1991), 31.
} 
had been lost in a modern mass marketplace in which music had been commodified. ${ }^{133}$ According to Adorno, a musician or chorister's ability to create and perform at an artistically high level ends up being less important to success than access to consumers. In his view, musical artists risked being debased by paid employment. Adorno's analysis did not capture the case of professional choristers. They are paid to work but do so in non-commercial, not-for-profit contexts that are largely marginal to the cultural industries Adorno reviles.

Pierre Bourdieu takes a different approach. He writes on the ability of education to shape the cultural competences of artists. His contention is that artists' training equips them with cultural competencies in the codes of their chosen art. Distinctions of taste classify them as bourgeois or upper class. ${ }^{134}$ In Bourdieu's conception, a musician is able to practice their art because they have been immersed in its codes of practice through either formal or informal education. Accordingly, professional status would be accorded those who have mastered the competencies that distinguish them as exemplars of their art.

Jacques Attali, in contrast, regards the musician as, historically, akin to the priest and officiant. ${ }^{135}$ The musician is simultaneously the reproducer of musical heritage and a prophet in their pioneering of new music. This raises them above the social hierarchy and glorifies them as superhuman. ${ }^{136}$ Attali's discussion invokes the magic of musicmaking. A chorister would qualify as professional for their ability to achieve the pinnacle

\footnotetext{
133 Ibid., 32-33.

134 Pierre Bourdieu, Distinction: A Social Critique of the Judgement of Taste (Cambridge: Harvard University Press, 1984), 2-7.

135 Jacques Attali, Noise: The Political Economy of Music, Trans. by Brian Massumi (Minneapolis: University of Minnesota Press, 1989), 11.

${ }^{136}$ Ibid., 12.
} 
of musical quality and in so doing achieve a status akin to an Olympian or rocket scientist in comparison to the common person.

None of these three scholars attempt to define the term professional chorister, yet they offer some insight into how scholars have approached the issue of professionalism for artists, providing context for discussing how it might be defined. Mitchell and Karttunen of the Arts Council of Finland make it clear that one cannot ask "who is an artist" without making subjective value judgements. Arbitrary aesthetic distinctions always feed into such judgements. ${ }^{137}$ This noted, they identify at least four types of ways of defining artists: self-definition, definition based on production, definition of the artist by the society at large, and definition by peers. ${ }^{138}$

Self-definition as an artist is as it sounds: the artist themselves makes the determination. The risk here is that it is done as a matter of self-promotion or to legitimize oneself as sufficiently proficient or experienced to warrant membership in the group ${ }^{139}$ Definition based on production measures the amount of art made by the artist and sees professionalism residing in regular artistic activity accompanied by an audience and/or commercial success. ${ }^{140}$ The definition of the artist by the society at large places the onus in the artist-audience relationship on the latter rather than the former. There are some accompanying markers of artist status such as notable privileges conventionally bestowed on this group, including the provision of support for

\footnotetext{
${ }^{137}$ Ritva Mitchell and Sari Karttunen, "Why and How to Define and Artist: Types of Definition and Their Implications for Empirical Research Results," in Cultural Economics, ed. by Ruth Towse and Abdul Khakee (New York: Springer-Verlag, 1992), 176.

138 Ibid., 179-180.

139 lbid., 179.

140 Ibid., 179-180.
} 
their work through taxpayer-funded programs and policies. ${ }^{141}$ Finally, definition by peers is relatively self-explanatory. It can denote conformity with mores and practices within an artistic community, but can also include formal criteria, such as training and education, and/or the quality and quantity of production as judged by peers. ${ }^{142}$

In each of these cases, Mitchell and Karttunen are interested in the definition of artist for the bureaucratic purposes of the Finnish Arts Council. Yet for the purposes of this paper, they offer a framework to understand what the definitions to come do and do not represent. The evidence provided by the interviewees in this study shows that for them, the first and last of the four criteria described above, self-determination and definition by peers, are the critical determinants of professionalism. The statistics compiled by the Canada Council and Choral Canada and presented previously define choristers by their output. The interviewees' definitions differ markedly.

In reflecting on definition by self-determination or by peers, it is helpful to discuss Becker and Carper's seminal paper on "The Development of Identification with an Occupation" (1956). Becker and Carper interviewed graduate students of physiology, mechanical engineering, and philosophy regarding each individual's feelings about their vocational identity and how they changed over time. ${ }^{143}$ They discuss a number of factors that contribute to vocational identity: the development of interest and acquisition of skill; initiation into the ideology of the chosen profession, often through informal participation in social groups; the internalization of motives of those within the profession, which rationalizes the logic of one's own professional choices; and

\footnotetext{
141 Ibid., 180.

142 Ibid.

143 Howard S. Becker and James W. Carper, "The Development of Identification with an Occupation," American Journal of Sociology 61, no.4 (1956): 290.
} 
sponsorship, or opportunities which emerge through the support of peers and mentors. ${ }^{144}$ It is also worth noting Kadushin's research into self-conceptualization as a professional by students in music studies programs of conservatories such as Juilliard and the Manhattan School of Music. It points to a further key element: actual participation in professional performance. By virtue of these schools' location in New York City, a thriving musical hub, and their reputation for the production of capable performers, students develop a sense of themselves as professionals. ${ }^{145}$ While Becker and Carper's research focuses solely on male graduate students in academic programs, the factors they discuss, in conjunction with Kadushin's nod to the influence of working as a professional, are evident in professional choristers' self-conceptualizations. These scholars' analyses accord with Mitchell and Karttunen's concepts of identity through self-determination and production. The takeaway for our discussion of chorister professionalism is that the experience of producing art accumulates to the point that it prompts the artistic practitioner to self-identify as a professional in their chosen field.

Scholars have attempted to explain the logic of career choice and identity as an artist as a result of a calling or a passion that eclipses economic considerations. Jaffee Nagel connects musicians' career choice to decision-making processes in adolescence and young adulthood during which individuals "synthesize their sameness, their differences, and the continuity of their parts as part of a process that results optimally in a definition of self." ${ }^{146}$ Based on Marcia's typology of commitment to one's occupation,

\footnotetext{
144 Ibid., 297-298.

145 Charles Kadushin, "The Professional Self-Concept of Music Students," American Journal of Sociology 75, no.3 (1969): 403.

146 Julie Jaffee Nagel, "Identity and Career Choice in Music," Journal of Cultural Economics 12, no.2 (1988): 69.
} 
Jaffee Nagel offers four logics for a musician's career choice: 1) Identity Achieved those who seek careers in music after careful reflection on alternatives; 2) Identity Foreclosed - those who never considered a path other than music, the logic and drive of which is derived from external influences, such as parents, teachers, and/or audiences; 3) Identity Moratorium - those who are currently in crisis about their career in performing arts and continue to weigh alternatives; and 4) Identity Diffused - those may pursue music professionally while also deriving equal satisfaction from other professions. The paper offers few conclusive thoughts, but it does raise two considerations that are useful to emphasize for the purposes of this paper. First, one's upbringing and education undoubtedly shapes both one's subsequent attraction to a career as a musician and the cultural capital one brings to that endeavour. ${ }^{147}$ Second, one's identity as a professional musician is neither linear nor static. One may fall into any or all of the above categories of definition as an artist, and do so to varying degrees at different times. Moreover, many musicians, choristers included, lead double careers, and can be defined as different types of professionals simultaneously.

This influence of passion indifferent to economic risk is also borne out in Wheeler's "double lives," a famous example of which is Paul Newman's work as both a film actor and a racecar driver. ${ }^{148}$ His key idea is simple: "work, if it ever did, no longer provides a full sense of vocation." He writes not of hobbies or leisure activities, but of "preoccupations - things so important to the self that it is hard to get them off one's mind and out of one's thoughts." ${ }^{149}$ Factors such as the changing nature of work, in

\footnotetext{
${ }^{147}$ Ibid., 70-74.

148 Stanton Wheeler, "Double Lives," in The Nature of Work: Sociological Perspectives, ed. by Kai Erikson and Steven Peter Vallas (New Haven: Yale University Press, 1990), 141-142.

149 Ibid., 143.
} 
terms of both time-consumption and effort required, weakening institutional networks, familial or religious, shifting values of society, or the economy's shift from an emphasis on production to consumerism all contribute to a heightened focus on preoccupations or vocations beyond one's conventional work.

While this discussion is designed to outline some of the logics in play in a professional chorister's choice of work, it also speaks to the ability of individuals to develop a distinctive sense of self through their preoccupations as much as their occupation. Though Wheeler does not argue it conclusively, he notes that many preoccupations have their roots in events of childhood or adolescence, an assertion similar to that made by Jaffee Nagel above. Finally, he notes that those with double lives may choose their work to align well with their preoccupation (work is chosen because it fits with the preoccupation, in that waiting tables allows a young actor the time to turn their preoccupation into an occupation), or to bend their work to fit their occupation, as a fireman who works nights might do in order to be able to golf during daylight hours. ${ }^{150}$

In his study of London musicians, Paul Cottrell examined the conundrum faced by gigging artists in their everyday lives. Given the plethora of work available to professional musicians in London(also referred to by Kadushin above), freelance musicians maximize their work opportunities by engaging in quite literally more work than they can do. ${ }^{151}$ In choosing between gigs, he returns to Pierre Bourdieu's concept of cultural capital. As alluded to previously, cultural capital is acquired through "early, imperceptible learning, performed within the family from the earliest days of life and

\footnotetext{
150 Ibid., 144-147.

151 Cottrell, Professional Music-Making, 60.
} 
extended by a scholastic learning which presupposes and completes it." He also deploys Bourdieu's concept of social capital, which is defined in terms of prestige, reputation, and fame. Both can translate into economic capital, which is the accumulation of financial power. ${ }^{152}$ Cottrell coins a new, more specialized term, musical capital, which

can be seen as a measure of the desirability, from the musician's point of view, of their participation in the event, as well as its value to them as they seek to establish a reputation and profile for undertaking particular types of work within their professional world. ${ }^{153}$

This capital is accrued throughout a musician's career, as opposed to solely through education and training. It is evident often in biographies or CVs as an assertion of professional profile and rank.

Examples relevant to our study may include work in a professional choir, participation in tours or recordings, and/or performances as a soloist. Musical capital is also discerned by the individual musician, who is conscious of the amount of it to be found in competing events. Therefore, a musician's conception of self or their selfinterest in accumulating musical capital is represented in the choices they make between professional opportunities. Cottrell wisely addresses the obvious concern that professional musicians are not free to simply choose the gigs found most rewarding, but can also be constrained by economic imperatives, by acknowledging each version of capital as an axis of a decision-making graphic.

Figure 1 below demonstrates these relationships in the context of a professional chorister from my own perspective. Along the $\mathrm{x}$ axis lies the musical capital, with

\footnotetext{
152 Bourdieu, Distinction, 66; Pierre Bourdieu, Language and Symbolic Power (Cambridge: Polity Press, 1991), 230

153 Cottrell, Professional Music-Making, 65.
} 
opportunities further to the right representing those with greater perceived payoff than those to the left. The y axis includes the economic capital, with those higher representing those more economically lucrative than those towards the bottom.

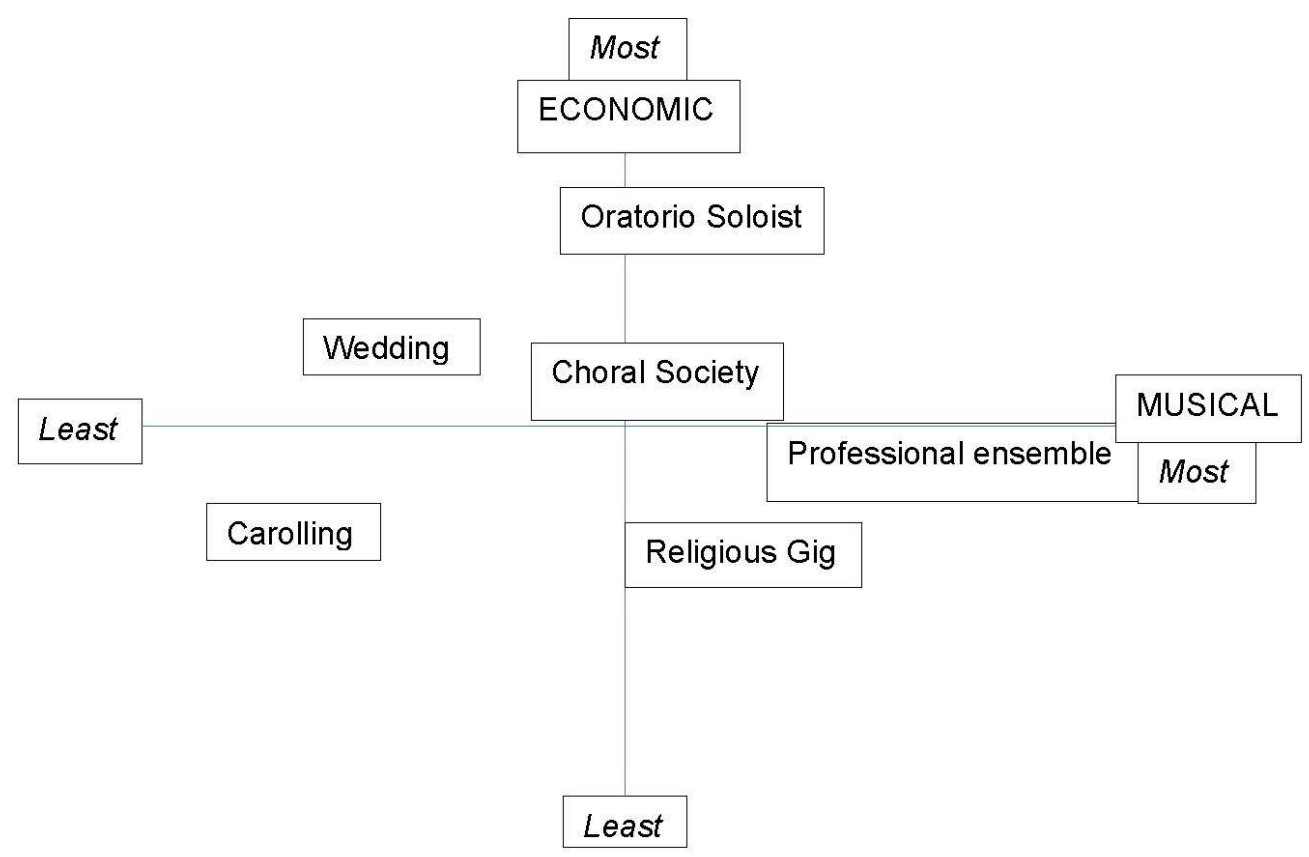

Figure 1: Economic and Musical Capitals - Professional Chorister, Walker As with Cottrell's graphic, this assessment represents solely my own visual representation of the relationship of these capitals rather than an attempt to represent that of my interviewees or professional choristers more generally. This is indeed the point: "the desirability of certain types of work changes from one musician to another for many complex reasons: career aspirations, musical tastes, sociomusical connections and so on...." ${ }^{154}$ This graphic, however, does provide a visual representation of my biased valuation of work as a professional chorister. It assigns work as a professional

154 Ibid., 68. 
chorister more musical capital than potentially more lucrative work as a soloist. Others with different ideas of self would generate a different graphic. In the next section, I will return to these concepts in the discussion of the choice of work for professional choristers.

The above review of the scholarly literature reveals no consensus definition of what makes a professional artist. Indeed, it points to two contradictory streams of selfidentification as professional. In one, the determination stems from a passion for the vocation that is indifferent to financial reward. In the other, a professional chorister is simply one who is paid for their work. This dichotomy is borne out in the testimony of interviewees for this study.

When asked to discuss their self-determination as a professional chorister, time and again interviewees struggled to come up with a response. They pointed to certain skills, such as sight-reading, musicianship, and collegiality, as key to becoming as proficient as possible at their work. However, choristers consistently derived their sense of professional status from their consistent record of work and external validation through payment. This section will explore these concepts further. It will conclude with a consideration of the relationship between a group of cultural workers who qualify as professionals and the cultural policy model that largely overlooks them.

Consistently, professional choristers identified money as the crux of what differentiates them from amateur singers. The following are a series of excerpts from interview in which this point was made:

Well, I was told, I think, back in my undergrad that if you're being paid to do something, you can consider yourself a professional. So, if you are consistently 
being paid to sing in choirs and being invited back, not fired after one attempt, then you are a professional choral musician. ${ }^{155}$

If you're getting paid, you're a professional. You accept money, then you have to accept the responsibilities that go with it. Whether you do one gig or a hundred, I think the same conditions apply. If you're going to get paid, you better step up and fulfil your responsibilities. ${ }^{156}$

I do consider myself to be a professional choral musician. I think that if somebody gets paid to sing in a choir, they're a professional choral musician. That's how I would define it. ${ }^{157}$

Money. One gets paid, one doesn't. There might be some other factors, but when I'm trying to come up with my resume and list all of my professional choral experience, I date my professional experience from when I started subbing when I was 18 . It was a couple years before I had a regular job that I was actually hired for full time, and a few more years after that before I started earning a living that way. But, when people started paying me the professional rates, when I started replacing the professional singers when they had to be away, I started to think of myself as a professional. ${ }^{158}$

In each of these few examples, the bottom line is payment for work: if one is paid to sing in a choir, regardless of their own training, the quality of their work, the nature of the organisation, or any other factors, they qualify as a professional choral musician.

For other singers, compensation for a solitary gig as a professional chorister does not a professional chorister make. Further considerations of regularity of employment and the proportion of one's income derived from choral work build on this first element. An alto provides a neutral comment on this matter as an entry point into the discourse:

I think some of us make this a more substantial part of our living than others. It's a quite substantial part of mine, so I think if I've established myself as really anything in this city, it's probably as a choral singer. I think other people are

\footnotetext{
155 Interview - Alto, May 2020, 5.

156 Interview - Alto, April 2020, 5.

157 Interview - Soprano, May 2020, 7.

158 Interview - Soprano, April 2020, 10
} 
professional choral singers, but they make more of their living doing other kinds of work, whether musical or non-musical. ${ }^{159}$

For this singer, the substantial contribution choral work makes to their income and their status as a regular choral singer are the factors that make them a professional choral musician. This said, they confer the title onto others who may not share these elements.

This tenor is less generous:

What I'm trying to say that it has to be a big part, the majority of the money you make. I think you can work in a different profession as well and have another profession as a musician, as a singer. So, I think it comes down to some sort of regular thing where, okay, say, for example, I'm singing in Tafelmusik and I have that contract, but I could also be singing as a sub for different choirs, whoever needs me at whatever time.

So, in that sense, there is a regularity of singing in choirs whenever I'm called on to sing. ... I think that it needs to be your only income is from singing or choral singing in order to be a professional chorister. ${ }^{160}$

Another tenor elaborates on this thought:

My view is that to be a professional singer, it has to be the bulk of your income. I think to be a professional, you have to have studied it in some sense, made a conscious decision to pursue it professionally, and for it to be your livelihood. So, I think there's a difference between being a professional singer and singing occasionally at a professional level. ${ }^{161}$

They continue:

(There are) lots of people who have other careers, whether they're professional careers like mine or just people with other jobs or they derive from completely different activities, but I think there're a lot of people in Toronto who are doing a lot of gig work, in and outside of music, to sort of cobble together a living.

And so, I'm lucky in that I have a career that sustains me financially and professionally and I can pick and choose what I want to dabble in singing as a hobby. I think a lot of people have their hand in a few different pots trying to cobble together all that income, some of which is singing, some of which is completely different. ${ }^{162}$

\footnotetext{
159 Interview - Alto, May 2020, 7.

160 Interview - Tenor, May 2020, 7.

161 Interview - Tenor, April 2020, 5.

162 Interview - Tenor, April 2020, 6.
} 
According to this point of view, those who may have qualified as a potential interviewee for this study on the basis that they had participated in a limited number of gigs as a paid chorister would not be considered professional choristers, but rather choristers paid to sing on occasion. As a final entry in this discussion, another bass hedges his bets:

If there's a degree to identifying as a choral musician, I'm probably at one end of that spectrum, because, probably like 90-95 percent of my income is made solely from choral singing. I don't know, maybe it's not that high. But, it's pretty high. The majority of my work, regardless of whether it's music or other artsyfartsy type stuff, it's primarily as a choral singer. So, I definitely consider myself a professional choral singer.

I know that there are other singers who sing professionally, and they may not describe themselves that way. I don't know. It's not for me to say. I would say that the people that I sing with, in my professional ensembles, like let's say a professional choir, I would say that they are professional choral singers. That's how I would describe them. I don't know if they would describe themselves that way. ${ }^{163}$

In other words, this bass identifies himself as a professional choral musician by virtue of the percentage of his income derived from choral work. Notably, he does not ascribe this definition to others, but rather leaves it up to them to judge for themselves.

This singer's reluctance to judge the worthiness of other singers to wield the title of professional chorister offers an opportunity to briefly discuss Mitchell and Karttunen's notion of external validation as a contributing factor in an artist's self-conceptualization as a professional. Building on the discourse around regularity and longevity as a professional chorister as evidence of identity, a bass refers to the elements of external validation he also wields to justify his logic:

Yes, I do consider myself (a professional choral musician). I think it's consistency in terms of work. It's also how long you've been in it ... What defines a

163 Interview - Bass, May 2020, 6. 
professional? In my mind, that means getting paid for your work. So, that means do I do things gratis? Not unless it's by choice. Unless I choose, for whatever reason, it's (a) fundraiser thing and fine, l'll offer my services. Tax receipt normally, something like that.

I would say, it's the fact that it's consistency being that I don't have, and I haven't had for years, (people telling me) well this would look good on your resume (in lieu of payment). That hasn't happened for a long time, because I've just been doing the gig for so long. And, what comes with that is the understanding from people asking for me that they know what they're going to get. They know that they can rely on that. There's a professionalism that comes along with that. ${ }^{164}$

The consistency of this singer's work over an extended period of time underwrites his self-definition as a professional chorister. It is also based on affirmation from others that his work is recognized as being of high quality. External legitimization is a critical in his self-conceptualisation. An alto concurs:

I would say that I am (a professional choral musician). Why am I a professional choral musician and why do I (myself) consider a more professional choral musician than other people?

I would say that because I sing in a professional capacity in a variety of different organisations. Also, because, no one expects me to sing for free. I think that in some ways that's in recognition of the talent and also, they set the expectation that I am professional, that this is something that is worth payment.

I think also that I don't accept things except for on very rare occasions where they're not offering payment in exchange for service. I would say that because I sing in a variety of fully professional choirs as well as section lead within voluntary choirs, both in an ongoing as well as (in a) ringer capacity. ${ }^{165}$

This external recognition of professionalism contributes to these choristers' identity as professional. It is interesting in this regard that both allude to expectations that they would work for free. This suggests that in some quarters at least the idea that choristers sing in order to make a living is still a foreign concept. On the whole, however, this testimony demonstrates that in forming a self-conceptualisation as a professional

\footnotetext{
164 Interview - Bass, May 2020, 3.

165 Interview - Alto, April 2020, 9-10.
} 
chorister, regularity of work, financial compensation, and external validation are key contributing factors.

Conversely, a reluctance to identify as a professional chorister can also be linked to economic output. This is evident in perceived lower status of choral work compared to solo work. Fearful of being typecast as "mere choristers", singers often choose the label of professional musician over that of chorister. ${ }^{166}$ This consideration is particularly relevant for emerging artists:

So, both from an artistic but also from, just say, a financial point of view, my aspirations were more towards the solo or high-level small ensemble world as a professional. But, when you're younger and particularly when you're still in school, it's very difficult to say no when you're offered paid choral work.

The downside of that, of course, is that you tend to get pigeon-holed in that world. People think of you as a chorister even if you are, as I believe I am, solo calibre. Once you've got a lot of choral stuff on your resume, it's hard for people to think of you otherwise. ${ }^{167}$

This conundrum is worthy of further reflection in the context of the gig work of many artists. In order to make a living wage, singers take on both solo and choral work, yet in doing the latter the pigeon-holing effect can put future soloist aspirations at risk. Others view this lack of differentiation as a badge of honour:

All of the money that I make is all music related, and I'm very proud that that's what I'm doing. Whether it be that I accept a small ensemble gig, or I accept a soloist gig, or I accept a teaching position or an adjudication or whatever it be, that surrounds my career choice, I'm successful at what I do. So, I don't call myself a chorister or a soloist. I'm a professional musician. ${ }^{168}$

These examples are evidence of a reluctance to self-identify as professional choral musicians. Both to prevent pigeonholing and to recognize the breadth of gigs they take

\footnotetext{
166 Interview - Alto, May 2020, 5.

167 Interview - Bass, May 2020, 6.

168 Interview - Alto, May 2020, 4.
} 
on singers choose to forego the label of professional chorister in favour of professional singer or musician.

The self-identification as a professional chorister on the bases of production and payment is further complicated by some choristers' emphasis on regularity. Channeling Wheeler, this singer alludes to their divergent goals and career choices which disqualify them from identifying as a professional chorister:

I think that, for me, no, I don't (label myself a professional choral musician). ... I've always kind of had this, a foot in both worlds. I've had this musical identity, but l've also been working in other fields. I've never really been able to sort of give one of those two streams my all. ${ }^{169}$

Despite this singer's paid work in professional choral settings, this dilemma is disqualifying for some others to consider one as a professional chorister:

My view is that to be a professional singer, it has to be the bulk of your income. I think to be a professional, you have to have studied it in some sense, made a conscious decision to pursue it professionally, and for it to be your livelihood. So, I think there's a difference between being a professional singer and singing occasionally at a professional level.

(There are) lots of people who have other careers, whether they're professional careers like mine or just people with other jobs or they derive from completely different activities, but I think there're a lot of people in Toronto who are doing a lot of gig work, in and outside of music, to sort of cobble together a living.

And so, I'm lucky in that I have a career that sustains me financially and professionally and I can pick and choose what I want to dabble in singing as a hobby. I think a lot of people have their hand in a few different pots trying to cobble together all that income, some of which is singing, some of which is completely different. ${ }^{170}$

This tenor disqualifies themself from identification as a professional choral singer based on their sources of income and regularity of engagement in the art form. This is a further

\footnotetext{
169 Interview - Alto, May 2020, 6.

170 Interview - Tenor, April 2020, 6.
} 
example of the professional chorister using economic criteria to define their identity within the field.

This kind of thinking is not shared by all choristers. For many interviewees, a love and commitment to the art form determines their identity:

...(F)or me, choir is my life. That, as a professional musician, was always my goal. I want choir to be my life. I don't really have that much interest in pursuing music really outside of that. ${ }^{171}$

Despite the intrinsic accessibility of choral singing, not all choral work is made equal.

Those who self-identify as professionals tend to have higher levels of musical capital than amateurs or semi-professionals. One interviewee chose to continue working as a professional despite indifferent economic returns because they were hooked on the higher level of performance involved:

I don't know, a lot of people have said to me over the years: if you love it so much, why not just do it as a hobby or something? It's because you just can't do it at the level as an amateur that you can as a professional. ${ }^{172}$

Others embraced choral singing despite it being perceived as a step down in terms of status. This interviewee felt that choral work suited her temperament more than solo work:

Possibly, depending on where I am in my life, I might have felt more like being a choral singer was maybe to, what is the word, subsidize a solo career as you were having a solo career take off.

I wasn't ever that interested in being a soloist, because like I say, I didn't have, I didn't grow up with classical music. I didn't grow up singing classical music, so I don't think that I developed the same kind of passion for being a solo musician. I'm not as natural a performer as other people: I don't get the same gratification from it.

\footnotetext{
171 Interview - Soprano, May 2020, 5.

172 Interview - Bass, May 2020, 9.
} 
So, I guess, once I stripped away teachers and coaches and other professionals, what their idea of being a professional singer was, I did land quite happily on considering myself a professional choral singer. ${ }^{173}$

For some, professional choral work is an exciting step up, for others a comfortable step down. As will be discussed in the next chapter, the work world of professional choristers is a diverse ecosystem with many ambiguous qualities.

This chapter has reviewed the academic literature surrounding the processes of self-determination and identification of professional artists. It reviewed relevant scholarship before attending to the testimony of professional choristers on this point. Like any vocational group, they were not unanimous in their opinions on this question. Yet some distinctive features are evident in their responses. Getting paid for their work was a key criterion in defining professional status. It was accompanied by regularity and continuity of employment through which significant work experience was acquired, along with a reputation in the field. Those who work regularly as professional choristers, receive payment for their work, and rarely work for free are likely to identify as a professional. Those who derive the bulk of their income from other sources or who do not perform as regularly, regardless of their quality as a singer, are less likely to identify as professional choristers. While some choristers mention their passion for choral music, in general choristers' professional status is determined by their ability to make a living from their art.

This conclusion is relevant to the broader context of cultural policy. Professionalism and economic viability are major criteria used by arts funders in recent decades to determine eligibility for government support. Choristers identify as

173 Interview - Tenor, May 2020, 4. 
professionals based on their ability to command payment in the marketplace. At the same time their work is integrated into an ecosystem of choral music in communities across the country that boasts high levels of amateur participation. One might expect that an art form that is highly popular and encompasses everything from grassroots enthusiasm to virtuoso accomplishment would qualify as a worthy object of government support. Yet the hidden nature of professional choristers and the segment of choir culture that best satisfies cultural policy funding criteria, means that their contributions get overlooked. Lacking a clear idea of the variety and quality of work that professional choristers produce, public funders remain indifferent to those who play a leading role in an art form that greatly enriches Canadians' lives. 


\section{Chapter Four: Institutions and Structures}

Thus far I have examined the different ways in which the contemporary federal cultural policy regime misapprehends and disincentivizes professional choristers. This chapter

discusses three factors that affect the training and support of workers in choral music: higher education, contract structure, and unionization. These factors are explored in order to understand structures other than cultural policy that could provide much needed material support for professional choristers. Since these structures are already integrated into professional choristers' working lives, reforming them may be a better approach to supporting professional choristers than relying on the vagaries of government patronage.

\section{A. Post-Secondary Education in Voice}

The last chapter concluded with a quotation from an interviewee who referred to their shift in self-identification as a professional chorister once they developed some critical distance from coaches', teachers', and other musicians' perspectives on their craft. This comment is not atypical. At the heart of this section on post-secondary institutions and structures lie concerns that they contribute to the stigmatization and misunderstanding of the work of professional choristers. In short, despite some inclusion of choral work in vocal performance studies, post-secondary institutions prioritise the soloist career path despite the prevalence of work available as a chorister. 
By way of entry into this topic, let us briefly review the scholarly literature on educational institutions and vocal performance. As we have seen, Bourdieu's theorization of social capital and class inspired Cottrell to coin the term musical capital. Bourdieu views the education system "as the principal institution controlling the allocation of status and privilege" through the "production, transmission, and accumulation" of cultural capital. ${ }^{174}$ Bourdieu writes that the task of the sociologist is to "determine the contribution made by the educational system to the reproduction of the structure of power relationships and symbolic relationships between social classes."175 While the analysis that follows is not directly concerned with how class structures are reproduced by the educational system, the spirit of Bourdieu's insight guides its discussion of post-secondary music education.

Walter's assessment of musical life as dependent on "trained professionals and enlightened listeners" guides his account of the development of music education in Canada. Performers become well versed in music theory, music history, centuries of repertoire, and technical training through years of preparation in specialized programs of musical education. ${ }^{176}$ Walter differentiates this music education from that for the listener, which permits the "music-consumer" to appreciate the complexity and artistry of music-making without imparting how to do it. ${ }^{177}$ In developing the latter, Bennett writes of the conservatorium, an institution which grew out of sixteenth-century Italian

\footnotetext{
174 David Swartz, Culture \& Power: The Sociology of Pierre Bourdieu (Chicago: University of Chicago Press, 1997), 189.

175 Pierre Bourdieu, "Cultural Reproduction and Social Reproduction," in Knowledge, Education, and Cultural Change, ed. by R. Brown (London: Tavistock, 1973), 71.

176 Arnold Walter, "The Growth of Music Education," in Aspects of Music in Canada, ed. by Arnold Walter (Toronto: University of Toronto Press, 1969), 248.

177 Ibid., 248-249.
} 
orphanages to become a widespread and influential cultural institution in Europe and beyond to the present day. ${ }^{178}$ Contemporary conservatories, Bennett writes, are faced with the challenge of preparing graduates to "meet the political, social, and economic demands of society through the provision of courses with more vocational or societal relevance." ${ }^{179}$ Critics of the conservatory often point to its seeming reluctance to change. Bennett cites Renshaw's key questions for music training institutions, which include:

graduates' preparedness for diverse careers, wide-ranging artistic practice, collaboration across the cultural industries, accessible professional development and advanced-level training, strategic partnerships, and diversity of courses. ${ }^{180}$

While this paper makes no claim to evaluate the musical educational institutions' progress in addressing these issues, they encompass the range of concerns raised by interviewees based on their experiences in vocal performance programs.

Before turning again to the testimony of the professional chorister interviewees, it is worth noting that cultural economists such as Ruth Towse have attempted to quantify the economic return professional singers receive on their investment in education. Towse alludes to the estimates singers make about their "chances of success," which is defined in terms of the "fabulous fees paid to top singers, even if hearsay reports are illfounded." 181 She concludes with comments about two aspects of the singing profession that are relevant to this study. First, Towse believes that singers' subjective assessments of their chances of success are too sanguine and that their miscalculation is enabled by the absence of objective information on the degree of risk inherent in the

\footnotetext{
178 Bennett, Understanding the Classical Music Profession, 57-59.

179 lbid., 59-60.

180 lbid., 61.

181 Towse, Singers in the Marketplace, 176.
} 
profession. ${ }^{182}$ The second aspect relates to uneven distribution of earnings amongst singers. MacDonald argues that the surfeit of low-income earners in the profession is attributable to beginners who are willing to survive on less than a living income while they try their luck in the field. Eventually they either drop out, find some work and perhaps build a composite career, or become reasonably successful. The continuous shakedown process in the profession depresses average wage rates.

The odds of success increase through success achieved. ${ }^{183}$ Put in layman's terms, the chances of getting future gigs are increased after one has been hired for the first one. Towse finds this tidbit of interest as it relates to risk assessment for singers. If they knew this prior to investing in a musical education, they would be better equipped estimate their future earnings and employment prospects objectively. ${ }^{184}$ What Towse overlooks, of course, is a factor discussed in the previous chapter. Many music students have grown up acquiring musical capital and have a passion for the art. They bring more to their education and take more from it than just money.

Interviewees attest that singers are made well aware, through their university experience, of the variety of careers to which a degree in vocal performance can lead.

One soprano explains:

... you just never know what paths people are coming to it from and which paths they're going to be taking away from it. People that we would've expected to just beeline for the performance stage went off and ended up doing a myriad of other things. l've run into some of those peoples in other choirs now and they're like, "Oh my god." You're like, "yeah, you didn't go off and have a solo career, because what, that's going to be $2 \%$ of people who actually graduate who are

\footnotetext{
182 Ibid., 176-177.

183 Glenn MacDonald, "The Economics of Rising Stars," American Economic Review 78, no.1 (1988);

Towse, Singers in the Marketplace, 177.

184 Towse, Singers in the Marketplace, 177.
} 
going to end up with some valuable, money-making career out of this." I don't know what the ratio is. ${ }^{185}$

This context is reassuring to a point, in that according to graduates, there is an awareness of the limitations and challenges of a career as a professional singer. Nevertheless, one alto reports on their understanding as an undergraduate of where choral music fit into their prospective career landscape:

... it's not a career. It's not something you're going to move forward with. It's something that you have to do until you can get into an opera chorus. ${ }^{186}$

This understanding demonstrates that despite some awareness of the broader careers available to those who study voice at the post-secondary level, choral music is often perceived not as an end in itself, but rather a means to a more lucrative career.

Despite its inclusion as a mandatory course in vocal performance and opera degrees described by interviewees, choral music seems to be undervalued in postsecondary settings:

Opera was definitely given a higher status in the program. If you were a soloist, you were assumed to have a certain really high level of skills that you didn't necessarily need as a choral musician. And so, the choral singing was really looked down on, especially, I think, by the private voice teachers in that school. It was not necessary. It was something that you had to do to get your degree, but not in any way something to aspire to. ${ }^{187}$

This pecking order is curious given the extensive presence of choral music in Canadian society and the relative scarcity of opportunities in opera. It makes little sense because choral performance is a key element of many an operatic soloist's career:

I would say that the general attitude was, for most of the people especially in the opera program that this was something you need to get over for your

\footnotetext{
185 Interview - Soprano, May 2020, 3.

186 Interview - Alto, April 2020, 4.

187 Interview - Soprano, April 2020, 2.
} 
requirement, I think, retrospectively, is ironic, because basically all you do as an opera performer is in the chorus which is just a version of being in a choir. ${ }^{188}$

If we reflect on Towse's comments, it will seem that post-secondary institutions are, in fact, doing a poor job of equipping students with the requisite information for a career in the arts. Despite the unsurprising revelation that undergraduate degrees do not provide students with all the skills they need for a successful singing career, it is also worth considering how these institutions perpetuate the hidden, misunderstood nature of professional choristers in the proverbial real world.

\section{B. Vocal Production: Stigmatized Technique}

Howard Swan, the prolific tenor and conductor, once noted that

authorities do not agree upon a proper vibrato rate for a singer, nor do they think alike concerning the importance of vocal registers, the modification of vowel sounds, and the establishment of a dynamic level to be used by a chorus for most of its singing. ${ }^{189}$

In other words, no two choirs will ever sound the same. This is attributable to the individuals who comprise the choir because there remains no unanimity on the amount of vibrato that is stylistically appropriate for a given piece or on other issues such as the proper shape of vowel sounds, and the establishment of dynamics. It is not just subjective sonoric preferences that bedevil conformity on these points. Singers also debate what constitutes healthy vocal technique. Yet the biases of coaches, teachers, and other advisors about these issues can derail a post-secondary student's career

\footnotetext{
188 Interview - Soprano, April 2020, 2.

189 Howard Swan, "The Development of a Choral Instrument," in Choral Conducting Symposium, ed. by Julius Herford and Harold A. Decker (Englewood Cliffs: Prentice Hall, 1973), 8.
} 
before it is started, marking them as choir material rather than destined for greater things.

Of course, dissonance on such matters creates a range of possibilities out of which every choir develops its unique sound. This in turn relates to the issue of "blend." A soprano described her early training in religious organizations and subsequent transition into postsecondary vocal education as follows:

My training was blend, blend, blend, blend, blend. Do whatever you can to blend. Do not stick out. Do not have a voice that has any colour other than the group sound.

(University voice teachers) spent, probably, the better part of three years trying to get me to stop doing that. Most of the coaches spent the better part of that time trying to get me to actually let go because it had been so drilled into me for so long that this was what you needed to be a good chorister. They weren't interested in grooming choristers. They were interested in grooming soloists. ${ }^{190}$

This illustrates the different educational standards that apply to prospective choristers.

This soprano offers a useful conceptualization of the stylistic choices of choirs in

Southern Ontario:

(Choirs operated under) this premise that you can have no vibrato. The premise that you need to sing through a pinhole. All those sorts of things that we've all heard singing, that we know some conductors do entirely work that way. But there are lots of conductors who actually support healthy technique.

But, back when I was at school in the university, we're talking 93-98 here, that was not the case. Choirs were pinhole choirs. Non-vibrato. Clean tone across all sections. The head of music around Toronto, the main conductor at that time was still Elmer Iseler. That was always his way: clean, pristine, thin, laser. ${ }^{191}$

When choral singers, conductors, and onlookers describe the necessity of blend or the use of straight tone, it is often this characterisation of choral vocal production to which they allude.

\footnotetext{
190 Interview - Soprano, May 2020, 3.
}

191 Ibid., 4. 
This issue raises concerns about whether a professional singer can produce the tone required for this style of music-making without compromising healthy technique. A soprano commented that:

The teachers at the faculty really shied away from that. They were really scared of what that would do to their singers' voices. Especially young voices that they were trying to shape and meld. ${ }^{192}$

While this paper is by no means focused on the academic debate on vocal technique, interviewees often alluded to it. In her comments on the pedagogy of post-secondary vocal performance professors and teachers, a soprano cited the work of a key author in this discussion, Richard Miller:

He's written several books on pedagogy from the seventies and eighties. Many of the current pedagogical thought comes from him. But, if you actually read through Richard Miller, it's so clear that he has a huge bias against any kind of straight tone, and therefore is worried about singing in choirs, even in university.

He doesn't really base it on that he's worried about vocal health. It's just that he aesthetically thinks that sounds bad. ... I would say, that is the reason people think choral singing is unhealthy, the singing with straight tone. ${ }^{193}$

Richard Miller's indeed comments disparagingly of the technique of professional singers in choral settings. He writes:

... (T)he threat to vocal health in choral singing lies not in decibel competition (such as through an attempt to hear oneself in a section) but in attempting to submerge the voice into the surrounding bland sound. ${ }^{194}$

Miller argues fervently that choral singers should not be required by choral conductors to remove the vibrato from their tone in order to create a blended sound. He goes so far as to comment that "there cannot be one vocal timbre that encompasses the entire

\footnotetext{
192 Ibid.

193 Richard Miller, On the Art of Singing (New York: Oxford University Press, 1996), 11.

194 Ibid., 58.
} 
group, unless the choristers are imitating a single vocal model, thereby falsifying their own voices." 195

Other scholars have weighed in on this debate. Walker found that trained adults and college singers are able to modify components of their vibrato. ${ }^{196}$ Yet, she also noted that "continual straight tone singing could compromise developing solo technique and possibly fatigue the voice."197 Similarly, Olson, while also writing of the merit of choral ensemble singing for collegiate-age singers, writes that singers should avoid non vibrato singing so as to avoid "undue stress on the vocal mechanism, insufficient air flow/breath support, incorrect muscle memory, spreading of the tone, pitch inaccuracy, lack of an overtone series, lack of "ring" in the voice, and loss of individual tonal quality."198

Others conclude that singing without vibrato can be done healthfully. Wasserman Gregg suggests that professional singers of early music can have the ability to sing with straight tone without progressing to tightened or pressed phonation. ${ }^{199}$ Sublett concludes, with the support of musicologists' research beyond North America, that there is insufficient research to conclude that non-vibrato singing is harmful. ${ }^{200}$ She continues on by noting, as this paper has done, that many singers go on to prolonged careers in choral music, and therefore, recommends that voice teachers coach students to achieve

\footnotetext{
195 Ibid., 63, 58.

196 Gayle Walker, “Vibrato, Science, and the Choral Singer," Choral Journal 47, no.6 (2006): 42.

197 Ibid.

${ }^{198}$ Margaret Olson, "The Solo Singer in the Collegiate Choral Ensemble," Journal of Singing 64 (2008): 563.

199 Wasserman Gregg cited in Walker, "Vibrato, Science, and the Choral Singer," 42.

200 Virginia Sublett, "Vibrato or Nonvibrato in Solo and Choral Singing: Is There Room for Both?" Journal of Singing 65 (2009): 540.
} 
the vocal aesthetic often required in these settings. ${ }^{201}$ This brief outline of the opinions of scholars who have written on the subject of straight-tone and blend offers a sense of the lack of clarity on the matter.

Professional choral singers interviewed for this project were primed to weigh in on this conversation. A soprano articulates the difference between vocal production for an opera role as compared to in a choir:

I don't think that the technical difference is as severe as people would make it out to be. Breathing is breathing, in my experience. Good tuning is good tuning. ... There is this idea of straight tone or reduced vibrato that is necessary depending on the conductor that you're working for, obviously, in choral music. ... I would say good technique is good technique and good musicianship is good musicianship no matter whether you're singing by yourself or with a section. ${ }^{202}$

In this regard, healthy singing goes far beyond vocal production in and of itself. Yet for singers who work both as soloists and as professional choristers, the technical differences between styles of vocal production can be taxing:

I come into conflict with it very often or used to come into conflict with it very often when I was trying to balance building a solo career while spending a majority of my singing time in a choral setting because, there's a lot of consolidation and a lot of compromise that comes with singing in a choir, which is part of what I enjoy about it. But then, you also find that you have to flip that switch off when you're singing solo work and it does take a toll technically. ${ }^{203}$

Indeed, the technical toll of straight-tone singing is simultaneously an area for potential harm, and intrinsic to the profession. An alto provides an analogy for the voice in this regard:

You need to have an understanding of the fact that the voice is an instrument, and it's not an instrument in the same sense that a violin is an instrument. It is a living, breathing, moving instrument that can be damaged with misuse. So, in the same sense if it's a violin, but it's like you're walking around with a violin without a

\footnotetext{
201 lbid., 541.

202 Interview - Soprano, April 2020, 2-3

203 Interview - Tenor, May 2020, 3.
} 
case. Potential for damage is high if you mistreat it, and repeated vocal trauma can create incredible pathologies if you don't take care of it. ${ }^{204}$

On this point, a consensus emerges. While the technique necessary to create the choral sound required for a given ensemble varies by ensemble and by singer, professional choristers reiterate the necessity for taking care to avoid vocal trauma.

Let us now return to Towse's risk assessment considerations. Through the testimony above, we have learned that vocal performance and opera programs do not emphasize choral music within their areas of study. Despite a mandatory choral performance course and the prevalence of choral music work in the Canadian music ecosystem, students are encouraged to focus on their technique and training towards a career elsewhere. This discrepancy is also present in the technical pedagogy of vocal production, wherein the tone often required for choral performance is discouraged in the name of voice health and, arguably, personal taste. The interviewees found that postsecondary institutions, the primary fora for study and training as a singer in Canada, do not adequately prepare them for work as a professional chorister. This bias of the academy gets reproduced in each successive generation of musicians, some members of which end up as cultural policy bureaucrats or serving on adjudication panels for grants. It fosters a general déformation professionnelle which feeds into a cultural policy that overlooks professional choristers.

${ }^{204}$ Interview - Alto, April 2020, 3. 


\section{The Economics and Workplaces of the Professional Choral Scene}

In the last subsection, I discussed some of Towse's analysis of the risk assessment required for those engaging with the professional music profession, and her linkage of this risk to the cost of associated postsecondary education. This analysis requires further thought with regard to the livelihood of the individual professional choral musician. This section relies on scholarly research into the financial situations of professional artists and singers. It will also allude to the workplace practices, including representation and treatment within professional choral work, in the choral scene more broadly. A deeper analysis of individual professional choristers' financial situations demonstrates the unique challenges they face due to diverse sources of income and lack of collective representation.

The struggling artist stereotype is often cited in connection with professional singers. According to Wassall and Alper, it has some basis in fact. There are some artists who enjoy great financial success. Apart from this minority, the earnings of singers vary tremendously with a mean lower than those other types of workers with comparable education. ${ }^{205}$ Yet artists' incomes are for the most part above the poverty line, especially if income from non-arts work is included. ${ }^{206}$ This analysis jives with the scholarly literature reviewed in Chapter Three, including Wheeler's concept of the double lives of contemporary workers. Figure 2 represents the information provided by professional choristers who responded to the following survey question: "prior to

205 Gregory H. Wassall, and Neil O. Alper, "Towards a Unified Theory of the Determinants of the Earnings of Artists," in Cultural Economics, ed. by Ruth Towse and Abdul Khakee (New York: Springer-Verlag, 1992), 197

206 Ibid. 


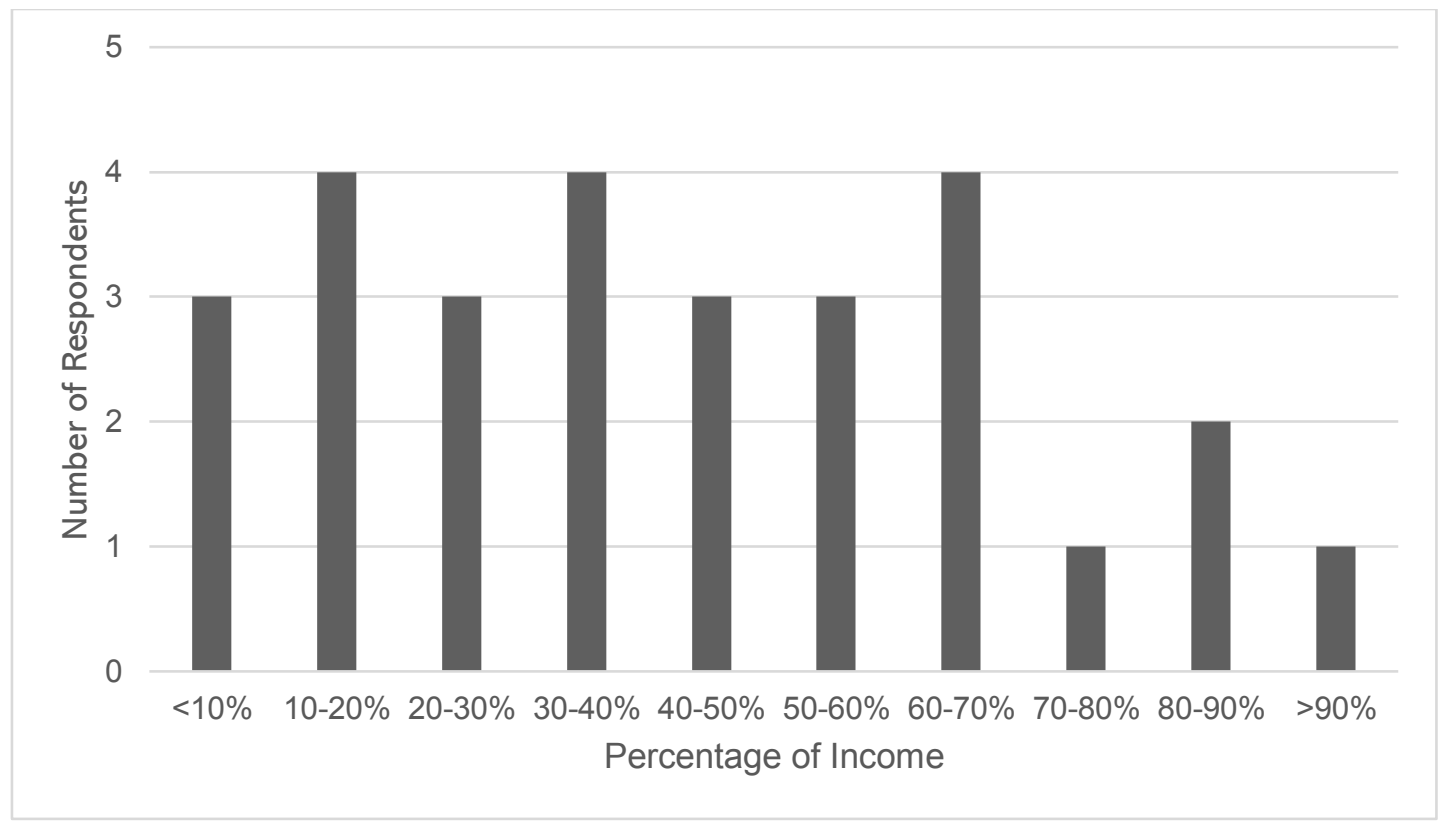

Figure 2: Percentage of Total Income Emanating from Professional Choral Music, prior to COVID-19207

COVID-19, what percentage of your estimated pre-tax income was from professional choral music work?" Each respondent was given the option of a range in ten per cent increments from less than $10 \%$ to over $90 \%$. It shows that less than 40 per cent $(11 / 28$ respondents) of professional choristers earn over half of their income from choral work. While this aspect of cultural economics holds true among professional choristers at a broad level, other economic indicators and workplace associated data offers a perspective on the variety of income levels within those interviewed. Among the 28 responses, Figure 3 represents the number of hours per week each interviewee engaged with professional choral work prior to the COVID-19 global pandemic. Based on this chart, the threshold is ten hours per week: an equal number of respondents allotted over and under ten hours of week for professional choral music work, with precisely none who worked more than thirty. Similarly, Figure 4 represents the number

207 Survey Responses, April/May 2020. 


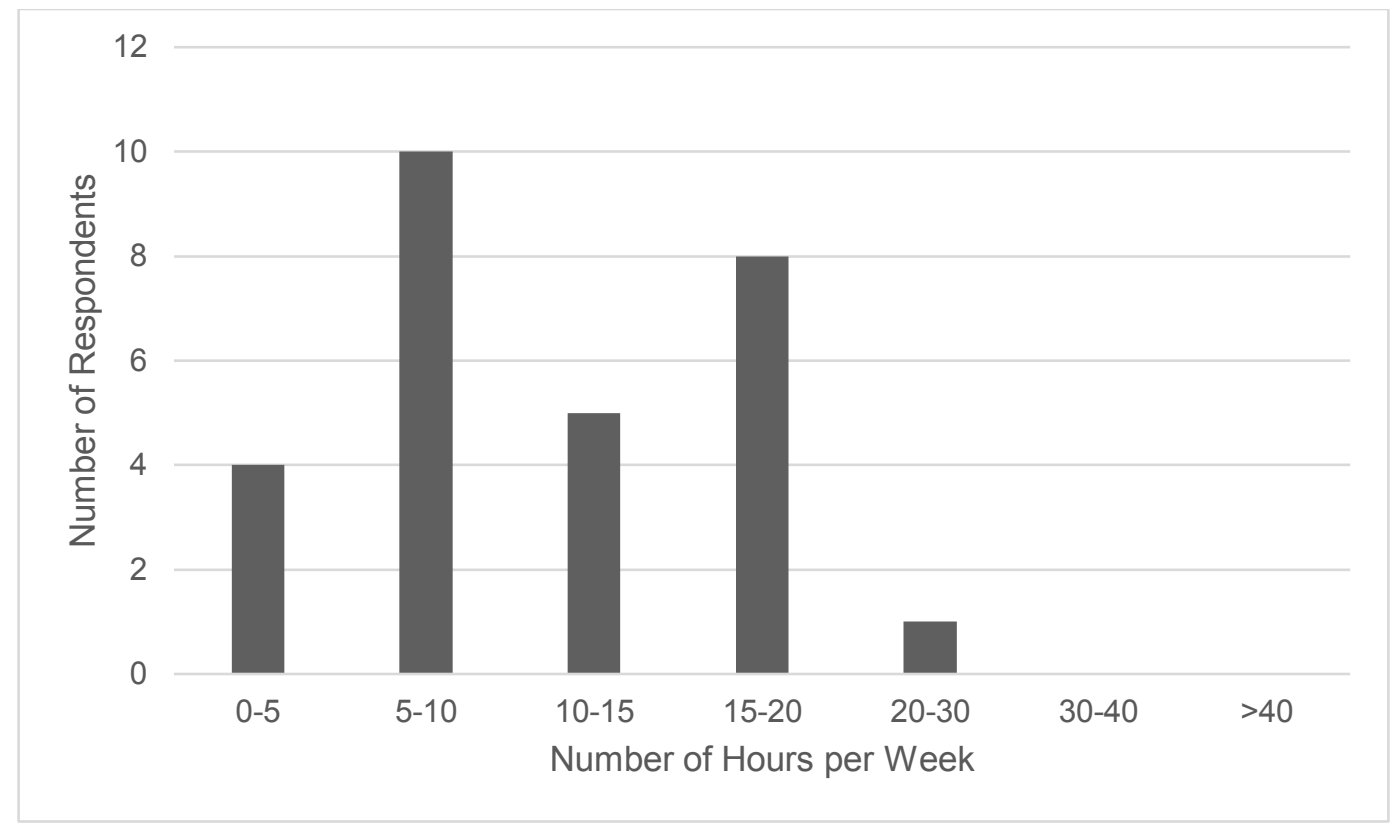

Figure 3: Number of Hours per Week of Work as a Professional Chorister prior to COVID-19208

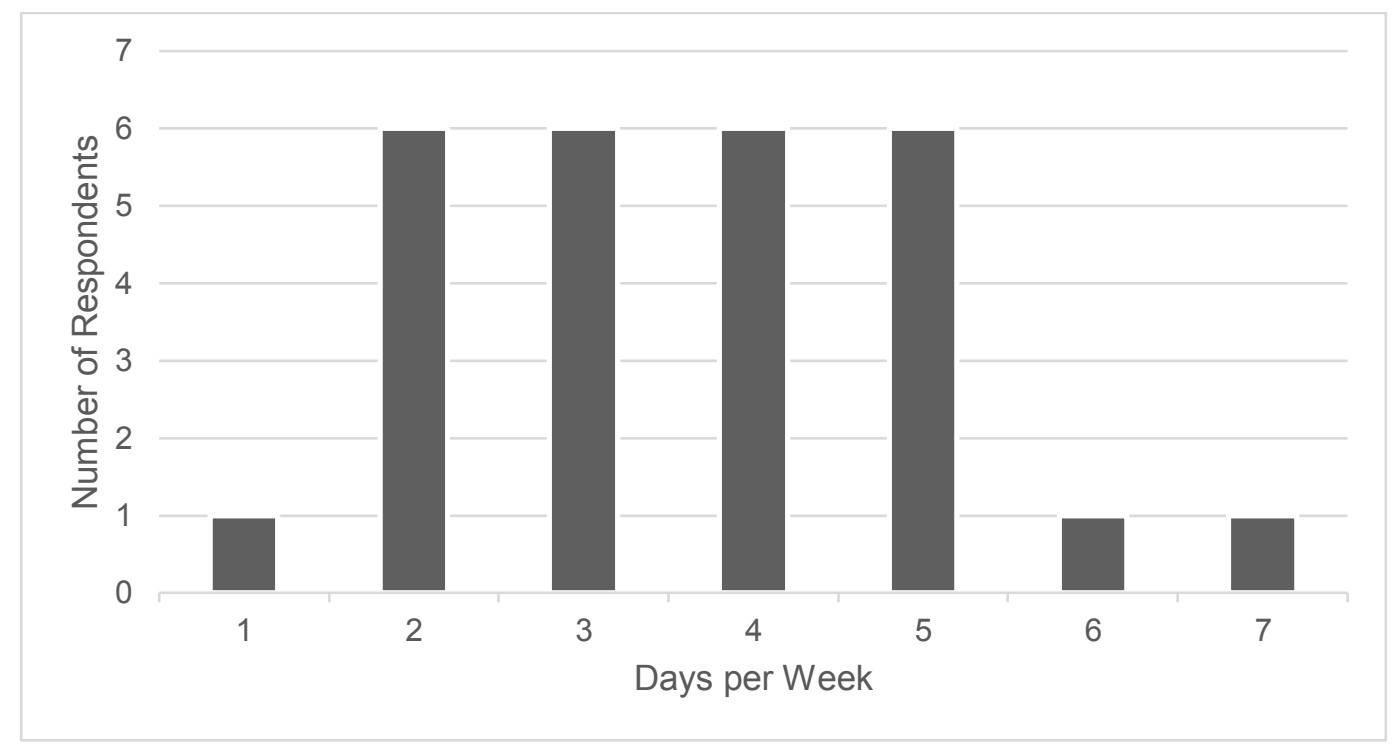

Figure 4: Number of Days per Week of Work as a Professional Chorister prior to COVID-19209

208 Ibid.

209 lbid. 
of days per week during which professional choristers worked prior to COVID-19. In this Figure, we can see that over $85 \%$ worked between two and five days a week. That percentage was divided equally between two, three, four and five days a week ( 6 of 27 respondents, or just over $20 \%$ for each number of days). These three graphs demonstrate the breadth of experience of professional choristers, both in terms of income and of time spent working.

A final statistic emanating from the survey associated with this study shows that choristers are not unanimous in their expectations for an hourly rate of pay. Figure 5 represents a consensus that they should receive around $\$ 25$ an hour, yet over $50 \%$ of respondents offered a different figure. While the variety in these responses is not as great as in the previous statistics presented, it graphically represents the precarity of choral work. An individual may work five days per week, with each gig offering a different rate of hourly pay and number of hours of work, and the lot combining

\begin{tabular}{|l|l|}
\hline Pre-Tax Hourly Rate (\$) & Number of Respondents \\
\hline 20 & 4 \\
\hline 22 & 2 \\
\hline 25 & 13 \\
\hline 27 & 1 \\
\hline 28 & 2 \\
\hline 30 & 3 \\
\hline Depends on the gig & 2 \\
\hline
\end{tabular}

Figure 5: Minimum Pre-Tax Hourly Rate Accepted for Professional Choral Work ${ }^{210}$

${ }^{210}$ Ibid. 
to constitute the bulk of their annual income. Simultaneously, the singer next to them may work three days per week at more lucrative gigs, all of which involve more time, and yet add an insubstantial amount to their annual income. Choral music organisations operate without industry standards and the more exploitative of them may play choristers off against each other to lower costs.

It is instructive to play around with the above figures to get a sense of the kind of living that can be made from choir work. In a best-case scenario, a chorister may work a maximum of 30 hours a week. This would be supremely unusual in the Canadian context (although it could happen in the course of a festival or recording session), not to mention physically taxing. Assuming they worked these hours and were paid at the highest rate of pay for an entire year (with two weeks off), their net income would be $\$ 45,000$ (30 hours/week x $\$ 30 /$ hour x 50 weeks/year). Most professional choristers fall well short of this income. As a rough estimate, a regularly working professional chorister might work 20 hours a week at $\$ 25.00$ per hour for 50 weeks a year. In that case they would pull in $\$ 25,000$, which would be a healthy income supplement but not enough to live on.

It is not only in income that professional choristers diverge in their positions and their experiences. Another example worth discussing is the nature of the contracts for the assorted gigs for which a chorister might be engaged. A bass outlines the variety in his contracts and obligations dependent on the type of work:

It's very different depending on who you're working with and at what level. The stuff that I do these days tends all to be union work. So, they're very, very contract conscious. Everything's quite explicit. Specifically, with (a professional choir in Quebec), where I am part of the Union des Artistes there. Everything's very regulated. 
(An Ontarian professional choir) had a letter of intent that you signed prior to the season saying yes, I promise I will sign the contract and sing all of the gigs. That was kind of a yearly thing.

I'm sure that I've signed things for church choir positions, but they were, I say perhaps, were a little bit less official.

Other groups, particularly a lot of pick-up groups, you might just be called upon to step in at the last minute to help out the section in a concert. Someone buys you a case of beer or writes you a cheque or something. So, there's a huge, wide variety. ${ }^{211}$

This extended quote offers an idea of the breadth of contracts available for professional choristers, thereby requiring a chorister to parse their own gigs and obligations along widely variable parameters.

Another chorister, in response to a survey question on steps that ought to be taken to support professional choral musicians, alludes to contracts when they recommend the following:

- Contracts with expected singer attendance levels, including sick day considerations. Addressing overtime and tour rates and expectations. Actually, getting contracts from employers.

- Sick pay will likely need extra consideration following this pandemic previously if I didn't attend, I wouldn't be paid, so there was a temptation to still go and sing while sick.

- Honestly, for long-standing (season-long) contracts, being made employees with standard source deductions would be nice.

- Ad-hoc gigs wouldn't need such agreements, but I do like to know how much I'm getting paid before I say yes, which doesn't always happen. ${ }^{212}$

As this singer points out, depending on the gig, a professional chorister may or may not have a contract or a clear idea of expected payment, may or may not have written expectations for cases such as overtime or touring, may or may not have sick pay, and

211 Interview - Bass, May 2020, 4.

212 Survey Response - April/May 2020. 
may or may not have tax and other deductions made from their paycheques, even under longer term contracts.

This variety is not necessarily correlated with the relative professionalism of choral music ensembles. An alto describes the variety of stipulations in contracts for similar gigs, in this case, professional ensembles:

For example, I knowingly have signed two contracts for very upper-level professional ensembles in Toronto or in the Toronto area, and one of them is extremely draconian in its measures. They are unwilling to compromise: once you've signed that piece of paper, there's no deviating from it. It means being present for $100 \%$ of those calls. It means you have certain obligations that need to be met.

The other group is not nearly as severe in terms of, there is a bit more flexibility involved with it. I think that it's based on a working assumption that there are a lot of pressures on people's time and everybody's not always going to be available for the same work. There are other people out there that might be able to fill in. It's not that big a deal.

Those are two kinds of approaches and different models to a contract-based approach. ${ }^{213}$

These two contracts offer a glimpse of the wide differentiation in contractual expectations for choristers. Some are lax, others strict. There are no common expectations of choristers; rights and duties fluctuate wildly from one gig to the next.

Choristers have spoken about how such inconsistency perpetuates precarity and uncertainty. They use the term "independent contractor" loosely to describe their employment status. It invokes the delimited contractual basis upon which they are hired, and their lack of benefits, deductions, and services to which permanent employees are entitled. One soprano describes their understanding of this term and its use in the professional chorister world:

${ }^{213}$ Interview - Alto, May 2020, 4. 
( $\mathrm{T}$ )hese organizations view me as a contractor, as an independent contractor. ... You are not offering me job security. I have to re-audition for this job every year. You pay me by the hour. I value this job and try to have a respectful angle there, but at the end of the day, being an independent contractor should come with that flexibility to be able to some extent choose your own hours. ${ }^{214}$

The professional chorister is hired by a series of organisations under different contractual standards that offer no consistent protections equivalent to the minimum employment standards enjoyed by full-time employees.

Moreover, the independence of the independent contractor doesn't work both ways. This soprano describes how the concept broke down when they attempted to negotiate her contractual arrangement with a choir:

They kind of were like, well, everybody signed it as it was. We can't let you sign this and not everybody else. It was me and another chorister who had both done this. I was like, I'm an independent contractor. What other people have signed should have no bearing on what I have signed.

But, this is where that kind of moniker of independent contractor falls out the window. They like to call us independent contractors because that absolves them of a lot of commitment and responsibility to us, but they don't really want to follow the rights, the characteristics that a relationship with an independent contractor would typically have. ${ }^{215}$

These characteristics of the independent contractor arrangement are raised by others as constant irritants in the institution-chorister relationship. As in the survey response above, an alto lists some of their concerns:

I would love to see a minimum call time. I would love to see that there is a certain amount of time, a cancellation time. If something is cancelled within two weeks, you're still paid for it. I would love to see some sort of uniformity. I would love to see standardized audition practices, some sort of standardized commitment expectation. I would love to see organisations working together so that they actually understand that, I'm not theirs. If you want to hire me as an independent contractor, then I'm not an employee. And so, your expectations of me need to be different. ${ }^{216}$

\footnotetext{
214 Interview - Soprano, May 2020, 5.

215 Ibid., 6.

216 Interview - Alto, April 2020, 18.
} 
The labour market structure in which professional choristers are deemed independent contractors offers divide-and-conquer benefits for employers, undermining worker solidarity and inhibiting the potential for improvements in contractual arrangements. This situation is facilitated by a sectoral culture in which employer and employees are united in a good cause, trying to practice and promote the beauty of their art in an indifferent world. This enables employers to create agreements that best suit their needs. Expectations for choristers vary from institution to institution, but not within institutions, as demonstrated by the quote above. The meaning of independent contractor status is therefore inconsistent.

As independent contractors, professional choristers are disempowered in workplace politics. To an audience, they are the organization, but the permanent structure of the organization, where power resides, is its administration. A recent worrisome example concerned the conductor of the Toronto Mendelssohn Choir and Director of The Elora Singers, Noel Edison. He resigned from the former and was terminated by the latter in 2018 after allegations of sexual misconduct emerged. ${ }^{217}$ Within the context of the broader \#MeToo movement, involving arts organisations and businesses around the world, this was a hint of some of the potential for workplace abuse taking place behind the scenes.

The Globe and Mail raised questions about institutional knowledge of and culpability for such abuse:

\footnotetext{
217 Marsha Lederman, "Noel Edison Resigns from Toronto Mendelssohn Choir after Probe into SexualMisconduct Allegations," The Globe and Mail, April 24, 2018, https://www.theglobeandmail.com/arts/music/article-noel-edison-resigns-from-toronto-mendelssohn-choirafter-probe-intol.
} 
To what extent are management and boards - in particular at publicly funded organizations - accountable for the actions of their front men, their stars? What constitutes enabling? And if there were allowances made for bad behaviour, what should happen at the board and management level? ${ }^{218}$

The professional choristers interviewed for this study were asked about their

experiences with the \#MeToo movement. They spoke about its positive effects in calling out harassment and misconduct in the professional choral music world:

Now, we are standing up and we're saying that's enough. We're not going to accept this anymore. You don't get to choose somebody based on their appearance or reject somebody based on their appearance. You don't get to discuss their physical attributes publicly. You don't get to touch publicly or privately without consent.

To be safe in your work environment should exist in every single profession, no matter what, and the entertainment industry is suffering because it's just been too long that we've accepted this behaviour. So, I'm really pleased to say that this is going down and stopping. ${ }^{219}$

Although these admirable steps, in addition to others, are being taken by professional choral music organisations, the workplace structure of the professional chorister remains skewed by the power imbalance between so-called independent contractors and centralized authority.

One alto pointed to how boards and administrators control the workplace without being engaged with it, yet suggests that choristers themselves have to engage more with administration if they hope to improve things:

There are many ways in which our, I wouldn't say our rights, but like our ability to function within those groups is very much dependent on the upper level, whether its artistic direction or the administration of a group.

I think, if anything, for me, moving forward, I've been more aware and tried to be more present in conversations with the administrative side of things, just so that there's less of a concern of me being taken advantage of, whether it's financially

${ }^{218}$ Marsha Lederman, "What Happened at the Mendelssohn Choir," The Globe and Mail, September 29, 2018, https://www.theglobeandmail.com/arts/music/article-what-happened-at-the-mendelssohn-choir/.

219 Interview - Alto, May 2020, 8. 
or otherwise. If I'm electing to (work as a professional chorister), it's a matter of finding a balance. For somebody who does it full-time, who does it exclusively, finding yourself in a position like that would be just devastating. ${ }^{220}$

This tenor speaks of their concern with regards to the precarity of speaking out prior to recent changes:

What I did experience before was very much a feeling of being a cog in a machine as I felt, and I've said this, where I felt as if I had a trap door under me. I felt that I had to be very careful in terms of what I said, how I said it, how I did from one moment to the next, not necessarily musically, but just in terms of being, of getting too close to upsetting a situation.

I've witnessed a couple of things which were eyebrow-raising to be sure, but I never said anything because I felt that I would be potentially unstable as a result, or l'd be out. ${ }^{221}$

This tenor's characterisation of their experience is a familiar one, yet despite the \#MeToo movement, the systemic power imbalances of the chorister workplace continue. As independent contractors, professional choristers lack collective representation and the security required for advocacy. Their independent contractor status enables all manner of workplace abuse, from the most trivial microaggression to egregious breaches of trust.

A potential remedy would be collective workplace representation through unionization. In the survey for this piece, the majority of respondents (16/28) reported that they do not belong to a union as part of their professional chorister work. Those who do reported that they were members of CUPE, the Canadian Actors Equity Association, the American Federation of Musicians, IATSE873, or the Union des Artistes. Nevertheless, professional choristers enjoy little protection under Ontario

220 Ibid., 9-10.

${ }^{221}$ Interview - Tenor, April 2020, 12. 
labour law. Prompted by the Edison saga, Benjamin Stein analyzed the issue as follows:

Choral singers hired for concert performances in Ontario have no organized representation. There is no voice to speak for them as a collective in matters relating to contract negotiation, working conditions, rates of pay or workplace discrimination and harassment. Canadian television and film performers are required to join ACTRA. Theatre performers have the Canadian Actors Equity Association. Instrumentalists and vocal soloists have the Canadian Federation of Musicians, which is an affiliate of the American Federation of Musicians. The Canadian Opera Company's occasional use of an onstage chorus falls under the responsibility of the CAEA.

Professional choral singers are not a clear or precise fit for any of these organizations, and as a result they have fallen through the cracks. ${ }^{222}$

If a professional chorister gets work that happens to be covered by a union agreement, they benefit from the workplace conditions of that particular gig. But this happens only occasionally when they enter a workplace that has been unionized by other types of cultural workers. There is no consistency because they have no union of their own by which to address their particular workplace issues and develop a worker solidarity that can exert pressure on employers by restricting their source of labour.

This is not necessarily a Canada-wide problem. A soprano compares her experience in Ontario with that of Quebec, where representation exists. Although it is not a chorister-specific labour organization, it provides a means for levying complaints as a result of workplace harassment:

In Quebec, there's a union that you could go talk to. It isn't the government. It's not going to the police. It's not doing a human rights tribunal thing which is too daunting, I think, for some people to follow through with. But, it might be that in between thing that doesn't involve you going to the organisation that's involved.

222 Benjamin Stein, "Op-Ed | Canadian Choral Musicians Deserve Better" Ludwig van Toronto (blog). November 6, 2018. https://www.ludwig-van.com/toronto/2018/11/06/op-ed-canadian-choral-musiciansdeserve-better/. 
I think that's part of the problem right now. The only people to complain to are the people that're employing you. This person; if they choose to do nothing about it, well, that's the end of that, unless you're like, 'I'm going to go to the media.' It shouldn't, there should be something in between those two things. ${ }^{223}$

A number of factors militate against unionization. In the contemporary neoliberal politico-economic order, unions do not enjoy good press and the "independent contractor" moniker bestows symbolic if not financial capital. Any attempt to organize choristers would no doubt be represented as a threat to the economic viability of their employers, and thus to the survival of choral art generally. Meanwhile the issues of representation and divergence in contractual arrangements between organisations are consistently raised by professional choristers. ${ }^{224}$

Economic precarity, dubious contract practices, and a lack of workplace protections feed back into the principal argument of this thesis. Canada's federal cultural policy structure incentivizes professionalism and economic viability. Due to factors such as the nature of their art, status regimes in the music world, and biases of educational institutions, professional choristers are not protected as professional artists in the same manner as their soloist and instrumental musician counterparts. Though unions represent singers in other settings, choristers do not have one. They experience economic precarity, predatory contractual relationships, and workplace environments rife with potential for abuse.

Canada's cultural policy is not solely responsible for these ills. However, its lack of attention to community-based art forms that do not appear to be as professional as more celebrated sectors of the arts prevents it from recognizing an opportunity to

\footnotetext{
223 Interview - Soprano, May 2020, 11.

${ }^{224}$ Amanda Coles, "Creative Class Politics: Unions and the Creative Economy," International Journal of Cultural Policy 22, no.3 (2016): 469.
} 
support a form of culture that is popular, participatory, and professional. Choral music ticks all the boxes in the lists of criteria by which governments justify cultural funding, but the state can't see it.

\section{Longevity as Dictated by Health and Wellbeing}

Since the professional chorister is at the heart of this analysis, I would be remiss to omit testimony from choristers on their mental health and wellbeing — what might be called the hidden issues of these hidden artists. The chorister's primary focus of concern for their physical health is their instrument:

I would say, first of all, and that's something that I've personally experienced, you depend on the health of your instrument, on your own health in general. So, if something goes wrong, if it's something as minor as a common cold, you're out. Or, you can try to power through it, but it might damage you vocally for a while and then you're going to be out of work for an indefinite period of time.

So, maintaining vocal health and dealing with situations where your vocal health is not good can be very hard on mental health because if you are a professional choral musician, you financially depend on two little vocal cords in your throat. It can be very difficult to deal with that because they're invisible and you don't really know what you're up against if something goes wrong. ${ }^{225}$

The instrument involves more than just vocal cords, however. Unlike instrumentalist musicians, choristers' general physical, mental, and emotional health comprises the health of their instrument—or, in Marxist terms, one's means of production. Professional choristers are intimately connected to their voice as instrument. Of course, other musicians have mental health issues as well, but for professional choristers the voice is an extension of the self. This can result in positive effects, such as participation in a

225 Interview - Alto, May 2020, 7. 
meaningful social group and blurred self-other boundaries through synchronous multisensory stimulation. ${ }^{226}$ This said, there is also potential for the work of professional choristers to induce vulnerability and stress.

Like many freelancers, for professional choristers any illness creates the dilemma of balancing short-term pressure to produce, fulfill commitments and protect income against the need to recover and protect others from contagion. The obvious solution, sick days embedded in contracts, is rare. One bass describes his experience as a chorister at the Cathedral Church of St. James, under the former Director of Music:

Yeah, I mean, let's put it this way: when St. James Cathedral introduced sick days, and I think probably in a contractual year, you're only afforded one sick day, I think most choristers will probably attest to the fact that calling in sick is just not something that we think twice about. If we don't show, we don't get paid.

Not to mention that, fine, we don't get paid, that's one thing. But, you're disappointing how many other people that are reliant on you, whether you're a soloist or whether you're a member of a unit that is so relied upon that if you're not there, then things can fall apart very quickly. ${ }^{227}$

This bass's final point is particularly important in the choral context. Taking time away for illness may cause others to lose work or compromise the performance of the ensemble. One alto speaks to their positive image of one organisation, Tafelmusik, which has enacted policies regarding illnesses:

I think Tafelmusik is the only organisation that if you get sick, they will actually still pay you. I don't know if Elora does that, but Tafelmusik, if you call in sick, they won't dock you, which is amazing.

In fact, I have to say, we're really fortunate just right now because we're supposed to be doing a concert in two weeks' time (as of April 2020), and of

\footnotetext{
${ }^{226}$ Nick Alan Joseph Stewart and Adam Jonathan Lonsdale, "It's Better Together: The Psychological Benefits of Singing in a Choir," Psychology of Music 44, no.6 (2016) and Maria-Paola Paladino, Mara Mazzurega, Francesco Pavani, and Thomas W. Schubert, "Synchronous Multisensory Stimulation Blurs Self-Other Boundaries," Psychological Science 21, no.9 (2010).

227 Interview - Bass, April 2020, 9-10.
} 
course it's been cancelled [due to the COVID-19 pandemic], but they're going to pay us for it, which is really nice. ${ }^{228}$

The spectre of COVID-19 has brought this issue to the fore. A crucial consideration for decision makers will be managing absences due to illness, both for the wellbeing of individual choristers, and in order to create attractive workplace environments post COVID-19.

While mental and emotional health are considerations for all workers, for choristers there is a particular connection between them and the nature of their work. As one chorister explained:

It's very evaluative, working as a musician, certainly, that pressure to be perfect. Perfectionism, performance anxiety is a thing. It's not even just performance anxiety: it's like, "am I doing a good enough job for my conductor for my bosses? Are my colleagues noticing that l'm singing out of tune?" There's a lot that goes on in your head because of that. ${ }^{229}$

Performance anxiety can be exacerbated by competition, especially within soprano, alto, and baritone voice sections. Fellow choristers who are colleagues, perhaps even friends, are also competitors for future work:

Yes. It can be very, very competitive and that aspect of ... I mean, coming from my own experience as a soprano, that feeling of knowing that you could be replaced, literally you could be replaced at any minute. Another soprano walks in. They like them a little bit better. It doesn't matter what you've done in the past for that organisation. They might decide to replace you for the next year. You're just gone.

And so, I don't think that uncertainty breeds a lot of self-confidence or selfesteem. I think it also leads to nastiness between the singers themselves. So, I think that kind of workplace, feeling good in your workplace and knowing that your colleagues have your back and that they're working with you, is something. ${ }^{230}$

\footnotetext{
228 Interview - Alto, May 2020, 8.

229 Interview - Soprano, April 2020, 9.

${ }^{230}$ Interview - Soprano, May 2020,
} 
Lacking union protection and job security, choristers work with the constant stress of knowing they could be replaced at the whim of those with power at any time.

The interviewees for this study, which took place at the outset of the global pandemic, also discussed the mental health implications of the volume of work undertaken by professional choristers. As work is often based in Christian traditions and calendars, the chorister can go from languishing underemployed to overextended and stressed for intense stretches of time:

The sporadic nature of the job can be somewhat anxiety-inducing just because it's not a typical, Monday to Friday, 9 to 5 . I've talked about it being a seasonal occupation. So, in June, there is usually not a heck of a lot going on, and so hopefully you've made enough money during Easter and May and springtime to cover you for the summer, if you don't have any gigs in the summer. If you do have gigs in the summer, that's great.

Same with after Christmas. The dog days of January, I've heard people refer to. That's a very real thing. Sometimes you just don't have any work. So, I think that with it being so irregular, that can create anxiety in some folks. ${ }^{231}$

Unlike in other seasonal industries with public support in the off-season, such as fisheries, or unionized work, life as a professional chorister does not come with any means for mitigating a highly inconsistent workload.

(P)eople who rely on (professional choral music) as their main source of income are heavily taxed around the Christmas and Easter seasons where they're taking on fourteen Messiahs, many church gigs at once. Vocally, they're going to be strained. Physically, they're already feeling incredibly compromised. I can only imagine the emotional toll and the fatigue that sets in. Of course, that's going to play a big role in mental health. ${ }^{232}$

For those who do choose to enlist in as many gigs as are available to them, in order to make ends meet, the volume of work required in order to provide a livable wage can exact a toll of another kind:

${ }^{231}$ Interview - Bass, April 2020, 8.

232 Interview - Bass, April 2020, 10. 
Within this last year, again, now l've mentioned it twice that l've cut back. I think there's a really quick ceiling to this profession because there's only so much time you have in your life and your day. There're only so many conflicts you can have between organizations. So, you can't just continue to get more and more gigs because it's not realistic to fill your schedule. It's not possible to fill your schedule like that.

I think there was a time where I had jammed packed in so much. Sometimes it's fine, but sometimes, things like Christmas, sometimes fall, or Easter, whatever: I feel like sometimes I'm literally, not even figuratively, literally running from gig to gig. It's not just the physical exhaustion: it's mental exhaustion. ${ }^{233}$

It is illuminating to consider this predicament in relation to the musical capital generated by a gig. By virtue of the number of gigs required to maintain a living wage, and acknowledging the volume that occurs around major Christian holidays like Christmas and Easter, even the most rewarding of work can lose its value. Taking into account the unpaid labour of practicing and learning music, scheduling and managing gigs, and other associated administrative work, the professional obligations of professional choristers who are able to land significant work can be overwhelming. ${ }^{234}$

The pandemic has brought the inverse of this overwork, with singers who previously worked consistently finding themselves without any work at all. The future of work for professional choristers is unknown, and this puts their mental wellbeing and financial stability at risk:

I think that many of us, probably most, are professional singers because of things that are very difficult to describe in words. It feels like a calling. ... I think, trying not to get sort of too grandiose or overblown about it, I think it feels like sacred work to a lot of us.

If we find ourselves for some reason unable to perform that work, or that work that we feel called to do, it can be pretty devastating. I think right now a lot of us are experiencing something like this. But, even beyond, for instance, right now, I don't know at the end of this pandemic, which of the organizations who usually

233 Interview - Soprano, April 2020, 9.

234 Interview - Bass, May 2020, 9-10. 
employ me are still going to be financially solvent, are still going to be hiring me..$^{235}$

The context in which these comments were made has shifted greatly since May 2020, as has the federal government's general response to the plight of cultural workers through programs such as the Canada Emergency Wage Subsidy and the Canada Emergency Response Benefit, as well as investments through the Ministry of Canadian Heritage and the Canada Council for the Arts. ${ }^{236}$ This noted, the stress on mental health and wellbeing that professional choristers experience trying to make a living wage must be considered an ongoing concern. These issues will only be fully exposed if the veil that shrouds the profession is stripped away.

The ethnocultural specificity of the Anglican choral music legacy is another barrier to creating a welcoming workplace environment. One racialized singer explains their experience:

For me, I don't ever want to be involved with a service or an event that has to do with, gosh, what is it, it's not like last night at the proms, but like, there are certain services that glorify the Commonwealth but in a way that is very nostalgic for colonialism. I think it's important to celebrate the Commonwealth.

I think there are ways to glorify the Commonwealth by also recognizing what that means, the good and the bad of it. But, I also will draw the line at an event that I wasn't at, but I may have been at if I had said yes to subbing for someone, but I couldn't that weekend. But, I was like, I am so glad that I didn't blindly have to say yes to this because it ended up being a very pro "England was a great empire across the world" and, you know.

So, I think there are certain considerations there where it's like, if ever I get asked to sing at any event like that, I will say no, I don't care what other considerations there might be.

235 Interview - Alto, May 2020, 11-12.

${ }^{236}$ Canada. Service Canada, "COVID-19 Benefits and Services," October 2, 2020, https://www.canada.ca/en/services/benefits/covid19-emergency-benefits.html and Canada. Canadian Heritage, "Emergency Support Fund for Cultural, Heritage and Sport Organizations," September 13, 2020, https://www.canada.ca/en/canadian-heritage/services/funding/information-covid-19/emergencysupport-fund.html. 
So yeah, (my level of comfort) depends. It depends on the people involved and the culture there. I would want to know that people of colour are welcome first. And usually, that's the nice thing about the gigs I've done: usually, there have been a lot of people I know and trust and am friends with. And then also, on the other side of the consideration coin, what is being sung and why. ${ }^{237}$

Inclusion of racialized and underrepresented communities within professional choral music is worthy goal that involves many tricky issues. Personal observation and anecdotal evidence suggest that racialized individuals are greatly underrepresented in the Southern Ontario choral scene. Comments like the above raise the question of whether organizations are doing enough to mitigate the colonial history of choral music in Canada. Choice of repertoire is a factor. Marginalized groups may be more likely to participate if they see something of their own culture in the mix. The choral scene is a microcosm of questions concerning multicultural integration in Canadian society as a whole. To what extent is it an irredeemably White Anglo cultural form in which any integration of racialized performers could be seen as an assimilative practice? Conversely, would full integration necessitate such wholesale change that the essence of the art form, inspired as it is by a particular ethnocultural tradition, would be lost?

This final section has spoken to the mental health and wellbeing of professional choristers in the context of their instruments, competition, the experiences of underrepresented and racialized communities, and both the plethora and precarity of employment opportunities in the market. Each of these considerations is worthy of study in and of itself. There is a wealth of scholarly literature on artists and musicians that has yet to be applied thoroughly to the situation of professional choristers. There are workplace solutions both within and outside the musical world that could be applied

${ }^{237}$ Interview - Tenor, May 2020, 12. 
constructively to improve the working lives of choristers, and, by extension, the health of the Canadian choral cultural scene in general. Moreover, as this study has consistently emphasized, the goals and methods of cultural policy should be reconsidered with the case of choral music as a dramatic example of its failings. 


\section{Conclusion: Considerations for an Artist-Centric Model of Cultural Policy}

This thesis began with the consideration of the choral music art form as one that inherently shields the individuals therein from the spotlight. Choral music relies on oneness, togetherness—-the ability to gel a multitude of talented musicians into a coordinated sound. The community of voices blended into one is the beauty of the art form, yet, as we have seen, a contributing factor in the misunderstanding and underappreciation of those who do it. These cultural workers, professional choristers, personify an ideal of communal cultural production, a shared experience between artists and audiences enhanced by professional participation and leadership. Despite the prevalence of choral music in Canadian society today, and indeed in the history of settlers on this land, previous scholarly work dedicated to understanding the lives of professional artists has all but entirely overlooked these workers. By describing the careers and work issues of professional choristers and reflecting on their position in Canadian cultural life and cultural policy, this study takes a step towards rectifying that deficiency.

As we have seen, professional choristers are not only an understudied layer of cultural worker, but a group whose art does not fit with the federal rationalization for arts funding. Professional choristers are similarly marginal in the academy and the labour movement. The historical status of choral singing in Canada reveals the role, or lack thereof, of the workers in the field in crafting the professionalized, commercialized and government supported high art of contemporary Canada. Comparing the community centre, communal approaches to culture and cultural policy proposed by artists of the mid-twentieth century with the choices of the Massey Commission and subsequent 
waves of cultural policy, culminating in today's neoliberal approach, shows that professional choristers work in a system that is built in a manner guaranteed to misapprehend their worth.

Through an autoethnographic methodological approach, borrowing primarily from the work of Stephen Cottrell, I embraced my personal and professional experience as a professional chorister and arts advocate in both accessing interviewees and analyzing their evidence. Professional choristers offered their time and reflections through interviews and surveys in Spring 2020, providing a first-hand insight into their work and lives. Rejecting any pretense of impartial objectivity, this paper wallows conspicuously in its biases, encouraging the reader to factor these in when assessing the validity of its conclusions.

In exploring this previously understudied area of cultural labour and output, information provided by the work of industry associations like Choirs Ontario and Choral Canada and by interviewees generated a detailed picture of professional choristers' employers and, to some degree, their livelihoods. Professional choristers' artistic talent, technical virtuosity and teaching skills enhance the artistry of choirs, enriching local cultural life and developing talent. Each of their very different types of employersprofessional ensembles, community choirs, religious organizations, various ad hoc gigs_-provides them with a different type of musical capital. At the same time, each, due to its size, assumptions, style of music-making, or compensation scheme, in some way reproduces the low status of the professional chorister.

The interviews revealed intriguing insights into the self-conceptualization of professional choristers as they attempted to define themselves as cultural workers. The 
secondary literature in the field helped interpret the information generated by these primary sources. Scholars such as Mitchell and Karttunen, Becker and Carper, Wheeler, Jaffee Nagel and others provided suggestive insights and frameworks for understanding how artists define themselves and make career choices. Professional choristers often tie their definition of themselves as professionals to the financial remuneration they receive for their work. There is a wide variation, however, in the scale of reward deemed sufficient. It can be measured by mere payment, a consistent expectation of payment, or a certain percentage of one's income being generated by choral singing. This last criterion was regularly cross-referenced to regularity and continuity of work, with those who derived significant portions of their income from other sources being less likely to identify as professional choristers.

Only after these factors were dealt with did other factors come into play. One might be considered professional if they had attained a high level of artistic accomplishment. Alternatively, one might be considered professional by virtue of being wholly dedicated to the art as one's vocation. Nevertheless, getting paid and making a living from choir singing trumped all such considerations. In the context of a cultural policy that is likely to underfund professional choristers, this yardstick hinders the growth of the profession.

Professional choristers face many challenges endemic to the institutions, structures and practices that constitute the choral music ecosystem. The research findings suggest that the academy does not emphasize or prepare students for lives as professional choristers. Instead, it highlights the virtue of professionalized solo work. It remains unclear whether this is a result of broadly accepted aesthetic choice or directly 
related to Towse's discussion of the economic output of professional singers. The standard rates of pay and the contractual arrangements of professional choristers documented here provide a benchmark for measuring whether the working conditions of professional choristers improve in the future. Problems with mental health and wellbeing are hazards of the profession, exacerbated by the fact that, as with all singers, a professional chorister's body is their instrument. An employment ecosystem in which employers hold all the cards and labour can be replaced at their whim is rife with potential for abuse. Professional choristers have minimal protection against workplace abuse. They lack an industry association to protect their voices, both literally and figuratively. Yet again, each of these institutions and structures is further evidence of a category of cultural worker that is hidden from view by virtue the art form itself, longstanding employment structures and practices, and policy decisions,

While this exposition has hopefully shed some light on this layer of cultural workers, its author will deem it a success if it encourages further research on professional choristers. Toronto is a special case, and we need to know more about professional choristers in different regions across Canada. An understanding of their circumstances in Quebec, for instance, where unionization and standardized rates of pay are higher, would make an illuminating companion study. Similarly, comparisons of urban and rural case studies would be welcome. There is, for example, a professional chorister labour market in Ontario outside the GTA, but it is unclear whether conditions in rural areas of other regions allow for one.

Further research into institutions such as the academy and the labour movement is also warranted. Currently, as we have seen, they are poorly adapted to the needs of 
professional choristers. The technical and pedagogical conversation on straight tone and blend is ongoing. Musicologists and sociologists would do well to consider its effect on the careers and self-conceptualization of choristers. While unions exist to protect cultural workers of the stage and recording studio, an analysis of why professional choristers are not protected by some like institution could point towards how they could be. Obviously, this prospect would have to be debated amongst choristers themselves, but they should be given the chance to consider it. Are there examples of artists in similar situations who have successfully embraced such a solution?

Adherence to the letter, if not also the spirit, of provincial labour policy is also a relevant consideration here. What would an artist-centric labour policy look like? Presumably, it would lift the veil which keeps professional choristers' work hidden and challenge the fiction that "independent contractor" is a viable and fair status given the conditions of employment they experience. The recent trend in cultural policy privileges industries in the sector, naively believing that the largesse of government subsidy will trickle down to cultural workers. There is an argument to be made that the aggregated labour of artists does more for Canadian cultural life than any corporate entity. It would follow that policy should focus directly on the artist and their livelihood rather than trusting in the neoliberal faith in the market to provide.

Questions about the proper jurisdiction and role of federal government cultural policy fit into this discussion as well. This paper's focus on federal cultural policy was driven in part by its prestige and the amount of money it brings to the table. Since cultural policy developed earlier at the federal level than at other levels of government, another reason for featuring it was that it helped frame the historical context outlined at 
the outset of the paper to situate the choral arts within the Canadian cultural scene as a whole. However, if it is agreed that professional choristers are worthy of government support, yet are also embedded in a cultural form that is inherently communal, local, and accessible, then should local governments play a greater role than federal in crafting policy to support them? Are, in fact, provinces or municipalities, the governments most familiar with regional differences and local cultures, best situated to appreciate and support choral music?

On the other hand, in dreaming of a better lot for choristers one is also reminded of the adage 'be careful what you wish for.' Foucault's vision of a state devising means of managing its population based on information derived from statistical feedback to various technologies of rule gives one pause. Perhaps professional choristers are better off being hidden from the government gaze. A glass half full perspective might conclude that they are getting by and getting to practice their art with some autonomy balanced with an integration into community life that makes it meaningful. Becoming subjects of cultural policy could change their professional orientation, skewing it towards fulfilling bureaucratic criteria and decontextualizing it from the very conditions that make it rewarding. Or, is there some happy place in between where professional choristers could game governmentality, showing enough of themselves to the state to win deserved support while retaining the essence of their craft?

It behooves professional choristers to consider whether tackling some of these issues could improve their professional and personal lives. It would take sustained effort over the long haul. It is a great irony of the professional choristers' predicament that their artistry involves practicing a communal ethic in artistic ensembles deeply 
integrated with communities, yet their professional travails derive from being divided as individual cultural producers who lack the solidarity necessary to improve their collective lot. It would be interesting to see whether applying their artistic ethic to political action would bear any fruit. 


\section{Bibliography}

Adams, Tony E., Holman Jones, Stacy Linn, and Carolyn Ellis. 2015. Autoethnography: Understanding Qualitative Research. New York: Oxford University Press.

Adorno, Theodor W. 1991. The Culture Industry: Selected Essays on Mass Culture. Edited by J.M. Bernstein. London: Routledge.

Attali, Jacques. 1989. Noise: The Political Economy of Music. Translated by Brian Massumi. Vol. 16. Theory and History of Literature. Minneapolis: University of Minnesota Press.

Becker, Howard S. 1951. "The Professional Dance Musician and His Audience." American Journal of Sociology 57 (2): 136-44.

Becker, Howard S., and James W. Carper. 1956. "The Development of Identification with an Occupation." American Journal of Sociology 61 (4): 289-98.

Bennett, Dawn. 2008. Understanding the Classical Music Profession: The Past, the Present and Strategies for the Future. Burlington: Ashgate Publishing Company.

Berland, Jody. 2013. "Applebaum-Hébert Report | The Canadian Encyclopedia." The Canadian Encyclopedia. December 15, 2013. https://www.thecanadianencyclopedia.ca/en/article/applebaum-hebert-reportemc.

Birch, Lisa, and Steve Jacob. 2019. “'Deliverology' and Evaluation: A Tale of Two Worlds." Canadian Journal of Program Evaluation 34 (2): 303-28.

Bourcheix-Laporte, Mariane. 2019. “Creative Canada: A Critical Look at a 'New' Cultural Policy Framework." CRTC. 
Bourdieu, Pierre. 1973. "Cultural Reproduction and Social Reproduction." In Knowledge, Education, and Cultural Change, edited by R. Brown, 71-112. London: Tavistock.

— 1977. Outline of a Theory of Practice. Cambridge: Cambridge University Press.

- 1984. Distinction: A Social Critique of the Judgement of Taste. Cambridge: Harvard University Press.

— 1991. Language and Symbolic Power. Cambridge: Polity Press.

Bowman, Durrell, and Gilles Potvin. 2015. "CBC Recordings | The Canadian Encyclopedia." In The Canadian Encyclopedia. https://www.thecanadianencyclopedia.ca/en/article/cbc-recordings-emc.

Bowman, Durrell, Wayne Riddell, and Helmut Kallmann. 2013. "Choral Singing; Choirs." In The Canadian Encyclopedia. http://www.thecanadianencyclopedia.ca/en/article/choral-singing-choirs-emc/.

Boylorn, Robin M., and Mark P. Orbe. 2014. Critical Autoethnography: Intersecting Cultural Identities in Everyday Life. Walnut Creek: Left Coast Press Inc.

Canada. Canada Council for the Arts. 1959. "Second Annual Report 1958-1959." Ottawa: Canada Council for the Arts. file:///Users/andrewjhwalker/Downloads/1958-59-Annual-Report-1.pdf.

—. 1969. "12th Annual Report." Ottawa: Canada Council for the Arts. file:///Users/andrewjhwalker/Downloads/1968-69-Annual-Report-1.pdf. . 1979. "The Canada Council 22nd Annual Report 1978-1979." Ottawa: Canada Council for the Arts. file:///Users/andrewjhwalker/Downloads/1978-79-AnnualReport.pdf. 
_ 2012. "2011-2012 Report." Ottawa: Canada Council for the Arts.

file:///Users/andrewjhwalker/Downloads/2011-12-Annual-Report.pdf.

_ 2017. "Performance Measurement Policy." Canada Council for the Arts. https://canadacouncil.ca/research.

_ 2020. "Open Data Table 2019-2020." Ottawa: Canada Council for the Arts. https://canadacouncil.ca/-/media/Files/CCA/Research/stats-and-stories/datatables/2019-20/en/opendatatable2019-20EN.xlsx.

—. n.d. "Applicant Profiles." Accessed November 25, 2017. canadacouncil.ca/Imedia/Files/CCA/Funding/Grants/ApplicantProfiles EN.pdf.

Canada. Canadian Heritage. 2017. "Creative Canada Policy Framework." Canada: Canadian Heritage. https://www.canada.ca/content/dam/pch/documents/campaigns/creativecanada/CCCadreFramework-EN.pdf.

— 2020. "Emergency Support Fund for Cultural, Heritage and Sport Organizations." September 13, 2020. https://www.canada.ca/en/canadianheritage/services/funding/information-covid-19/emergency-support-fund.html.

Canada Council for the Arts Act, Statutes of Canada. 1985.

Canada. Department of Communications. 1987. Vital Links: Canadian Cultural Industries. Ottawa: Government of Canada. http://epe.lacbac.gc.ca/003/008/099/003008disclaimer.html?orig=/100/201/301/ic/dc/FC95.4 .C3 Canadian cultural industri es vital links.pdf. 
Canada. Royal Commission on National Development in the Arts, Letters and Sciences. 1951. Report of the Royal Commission on National Development in the Arts, Letters and Sciences. Ottawa: King's Printer.

Canada. Service Canada. 2020. "COVID-19 Benefits and Services." October 2, 2020. https://www.canada.ca/en/services/benefits/covid19-emergency-benefits.html.

Chanan, Michael. 1994. Musica Practica: The Social Practice of Western Music from Gregorian Chant to Postmodernism. New York: Verso.

Choirs Ontario. 2011. "Ontario Choir Profile." Toronto: Choirs Ontario. http://www.choirsontario.org/downloads/2011 Choral Data Study - Final.pdf.

—. 2020. "About Choirs Ontario." 2020. https://choirsontario.org/about/.

Choral Canada. 2016. "Home." 2016. http://www.choralcanada.org/.

_. 2017. "National Choral Census." Toronto: Choral Canada. http://www.choralcanada.org/activities-projects/national-choral-census/.

Cohen, Anthony. 2002. Self Consciousness: An Alternative Anthropology of Identity. New York: Routledge. https://doi.org/10.4324/9780203418987.

Coles, Amanda. 2016. "Creative Class Politics: Unions and the Creative Economy." International Journal of Cultural Policy 22 (3): 456-72. https://doi.org/10.1080/10286632.2014.994612.

Cottrell, Stephen. 2004. Professional Music-Making in London: Ethnography and Experience. SOAS Musicology Series. Burlington: Ashgate Publishing Company. Edwardson, Ryan. 2008. Canadian Content: Culture and the Quest for Nationhood. Toronto: University of Toronto Press. 
Flew, Terry. 2012. The Creative Industries: Culture and Policy. London: SAGE Publication Ltd.

Florida, Richard. 2012. The Rise of the Creative Class, Revisited. New York: Basic Books.

Folkins, Tali. 2020. “Evensong Renaissance." Anglican Journal (blog). April 20, 2020. https://www.anglicanjournal.com/evensong-renaissance/.

Gattinger, Monica. 2017. The Roots of Culture, The Power of Art: The First Sixty Years of the Canada Council for the Arts. Montréal \& Kingston: McGill-Queen's University Press.

Hillman-Chartrand, Harry, and Claire McCaughey. 1989. "The Arm's Length Principle and the Arts: An International Perspective - Past, Present and Future." In Who's to Pay for the Arts?, edited by Milton C. Cummings Jr. and Mark Davidson Schuster. New York: ACA Arts Research Seminars Series.

Jaffee Nagel, Julie. 1988. "Identity and Career Choice in Music." Journal of Cultural Economics 12 (2): 67-76. https://doi.org/10.1007/BF02258421.

Kadushin, Charles. 1969. "The Professional Self-Concept of Music Students." American Journal of Sociology 75 (3): 389-404.

Kallmann, Helmut. 1960. A History of Music in Canada 1534-1914. Toronto: University of Toronto Press.

_. 1969. "Historical Background." In Aspects of Music in Canada, edited by Arnold Walter, 26-61. Toronto: University of Toronto Press. 
Kieser, Karen. 1988. "CBC Radio and Canadian Music Abroad.” In Hello Out There! Canada's New Music in the World 1950-85, edited by John Beckwith and Dorith R. Cooper, 14-23. CanMus Documents 2. Toronto: Institute for Canadian Music. Klein, Howard. 1967. "You Can Stay Home and Still Hear the Music of Canada." New York Times, 1967, sec. Arts \& Leisure.

Lederman, Marsha. 2018a. "Noel Edison Resigns from Toronto Mendelssohn Choir after Probe into Sexual-Misconduct Allegations." The Globe and Mail, April 24, 2018. https://www.theglobeandmail.com/arts/music/article-noel-edison-resignsfrom-toronto-mendelssohn-choir-after-probe-into/.

_ 2018b. "What Happened at the Mendelssohn Choir." The Globe and Mail, September 29, 2018. https://www.theglobeandmail.com/arts/music/article-whathappened-at-the-mendelssohn-choir/.

Lefebvre, Marie-Therese. 1994. "The Role of the Church in the History of Musical Life in Quebec." In Canadian Music: Issues of Hegemony and Identity, edited by Beverley Diamond and Robert Witmer, 65-74. Toronto: Canadian Scholars' Press Inc.

Litt, Paul. 1992. The Muses, the Masses and the Massey Commission. Toronto: University of Toronto Press.

MacDonald, Glenn. 1988. "The Economics of Rising Stars." American Economic Review 78 (1): 155-66.

MacMillan, Keith. 1969. "National Organizations." In Aspects of Music in Canada, edited by Arnold Walter, 288-313. Toronto: University of Toronto Press. 
Mascarenhas-Keyes, Stella. 1987. "The Native Anthropologist: Constraints and Strategies in Research." In Anthropology at Home, edited by Anthony Jackson, 180-95. London: Tavistock.

Merriam, Alan P. 1964. The Anthropology of Music. Evanston: Northwestern University Press. https://catalog.hathitrust.org/Record/006940043.

Miller, Richard. 1996. On the Art of Singing. New York: Oxford University Press.

Mitchell, Ritva, and Sari Karttunen. 1992. "Why and How to Define and Artist: Types of Definition and Their Implications for Empirical Research Results." In Cultural Economics, edited by Ruth Towse and Abdul Khakee, 175-86. New York: Springer-Verlag.

Mould, Alan. 2007. The English Chorister. New York: Continuum Books.

Olson, Margaret. 2008. "The Solo Singer in the Collegiate Choral Ensemble." Journal of Singing 64 (June): 561-64.

Paladino, Maria-Paola, Mara Mazzurega, Francesco Pavani, and Thomas W. Schubert. 2010. "Synchronous Multisensory Stimulation Blurs Self-Other Boundaries." Psychological Science 21 (9): 1202-7. https://doi.org/10.1177/0956797610379234.

Potvin, Gilles. 1969. "Performers." In Aspects of Music in Canada, edited by Arnold Walter, 143-66. Toronto: University of Toronto Press.

_ 1988. "Radio Canada International: The Voice of Canada after Forty Years." In Hello Out There! Canada's New Music in the World 1950-85, edited by John Beckwith and Dorith R. Cooper, 56-60. CanMus Documents 2. Toronto: Institute for Canadian Music. 
Stein, Benjamin. 2018. "Op-Ed | Canadian Choral Musicians Deserve Better." Ludwig van Toronto (blog). November 6, 2018. https://www.ludwigvan.com/toronto/2018/11/06/op-ed-canadian-choral-musicians-deserve-better/.

Stewart, Nick Alan Joseph, and Adam Jonathan Lonsdale. 2016. "It's Better Together: The Psychological Benefits of Singing in a Choir." Psychology of Music 44 (6): 1240-54. https://doi.org/10.1177/0305735615624976.

Strimple, Nick. 2002. Choral Music in the Twentieth Century. New Jersey: Amadeus Press. http://hdl.handle.net/2027/mdp.39015055167657.

Sublett, Virginia. 2009. "Vibrato or Nonvibrato in Solo and Choral Singing: Is There Room for Both?" Journal of Singing 65 (June): 539-44.

Swan, Howard. 1973. "The Development of a Choral Instrument." In Choral Conducting Symposium, edited by Julius Herford and Harold A. Decker. Englewood Cliffs: Prentice Hall.

Swartz, David. 1997. Culture \& Power: The Sociology of Pierre Bourdieu. Chicago: University of Chicago Press.

The Church of England. 2019. "Record Numbers of Visitors and Worshippers Flock to England's Cathedrals." The Church of England, November 26, 2019. https://www.churchofengland.org/news-and-media/news-and-statements/recordnumbers-visitors-and-worshippers-flock-englands.

Tippett, Maria. 1990. Making Culture: English-Canadian Institutions and the Arts before the Massey Commission. Toronto: University of Toronto Press.

Toronto Mendelssohn Choir. 2017. "Who We Are | TORONTO MENDELSSOHN CHOIR." 2017. https://www.tmchoir.org/who-we-are/. 
Towse, Ruth. 1993. Singers in the Marketplace: The Economics of the Singing Profession. Oxford: Clarendon Press.

Tuer, Dot. 1992. "The Art of Nation Building: Constructing a Cultural Identify for PostWar Canada." Parallelogram 17 (4).

—. 2005. Mining the Media Archive. Essays on Art, Technology, and Cultural Resistance. Toronto: YYZ Books.

Walker, Gayle. 2006. "Vibrato, Science, and the Choral Singer." Choral Journal 47 (6): $36-46$.

Walter, Arnold. 1969. "The Growth of Music Education." In Aspects of Music in Canada, edited by Arnold Walter, 247-87. Toronto: University of Toronto Press.

Wassall, Gregory H., and Neil O. Alper. 1992. "Towards a Unified Theory of the Determinants of the Earnings of Artists." In Cultural Economics, edited by Ruth Towse and Abdul Khakee. New York: Springer-Verlag.

Wheeler, Stanton. 1990. "Double Lives." In The Nature of Work: Sociological Perspectives, edited by Kai Erikson and Steven Peter Vallas, 141-48. American Sociological Association Presidential Series. New Haven: Yale University Press. Williams, Raymond. 1997. Marxism and Literature. Oxford: Oxford University Press. 


\section{CUREB A Clearance Certificate}

\section{Sarleton \\ Canaters Capital Uninersit:}

Office of Research Ethics

4500 ARISE Building | 1125 Colonel By Drive

Ottawa, Ontario K1S 586

$613.620-2800$ Ext 2517

ethics@carletonca

\section{CERTIFICATION OF INSTITUTIONAL ETHICS CLEARANCE}

The Carleton University Research Ethics BoardwA (CUREB.A) has granted ethics clearance for the research project described below and research may now proceed. CUREBAA is constituted and operates in compliance with the TriCouncil Policy Statement: Ethical Conduct for Research hvohing Humsans (TCPS2).

Ethics Protocol Clearance ID: Project \# 112629

Project Team Members: Andrew Walker (Primary Investigator)

Dr. Paul Litt (Research Supervisor)

Project Title: Professional Choral Musidians in Southem Ontarioc A Profile

Funding Source (If applicable)

Effective: April 13, 2020

Expires: April 30, 2021.

Please ensure the study clearance number is prominently placed in all recruitment and consent materials: CUREB-A Clearance $\# 112629$.

Restrictions:

This certification is subject to the following conditions:

1. Clearance is granted only for the research and purposes described in the application.

2. Any modification to the appeoved research must be submitted to CUREB*A via a Change to Protocol Form. $\mathrm{Al}$ changes must be cleared prior to the continuance of the research.

3. An Annual Status Report for the renewal of ethics clearance must be submitted and cleared by the renewal date Isted above. Failure to subenit the Annual Status Report will result in the closure of the file. If funding is associated, funds will be frozen.

4. A closure request must be sent to CUREB.A when the research is complete or terminated.

5. During the course of the study, if you encounter an adverse event, material incidental finding, protocol deviation or other unanticipated peoblem, you must complete and submit a Report of Adverse Events and Unanticipated Problems Form, found here: https: Icarleton.ca/researchethics/forms-and-templates/

Falure to conduct the research in accordance with the principles of the Tri-Council Palicy Statement Ethical Conduct for Research hwolwing Humsans 2nd Edition and the Carleton Uiniversity Policies and Procedures for the Ethical Conduct of Research may result in the suspension or termination of the research project.

Upon reasonable request, it is the policy of CUREB, for cleared protocols, to release the name of the PI, the title of the project, and the date of clearance and any renewal(s).

In light of the COVID-19 outbreak, The REB has developed guidance for human participants' research at

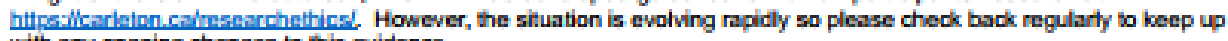
with any ongoing changes to this guidance.

Please contact the Research Compliance Coordinators, at ethics, Gearleton.ca, if you have any questions.

CLEARED BY:

Date: April 13, 2020

Natasha Artemeva, PhD, Chair, CUREB A

Janet Mantler, PhD, Vice-Chair, CUREB*A

This email contains links to content or websites. Aways be cautious when clicking on external links or attachments. If in doubt, please forward suspicious emails to phishing(i)carleton.ca. 